\title{
Distribution of impurity states and charge transport in $\mathrm{Zr}_{0.25} \mathbf{H f}_{0.75} \mathrm{Ni}_{1+\mathrm{x}} \mathrm{Sn}_{1-\mathrm{y}} \mathrm{Sb}_{\mathrm{y}}$ nanocomposites
}

Yuanfeng Liu ${ }^{1}$ ’, Julien P.A. Makongo ${ }^{1} \neq$, Alexander Page ${ }^{2}$, Pranati Sahoo ${ }^{1}$, Ctirad Uher ${ }^{2}$, Kevin Stokes $^{3}$, Pierre F.P. Poudeu ${ }^{1, *}$

1) Laboratory for Emerging Energy and Electronic Materials, Department of Materials Science and Engineering, University of Michigan, Ann Arbor, MI 48109, USA

2) Department of Physics, University of Michigan, Ann Arbor, MI 48109, USA

3) The Advanced Materials Research Institute, Department of Physics, University of New Orleans, New Orleans, LA 70148, USA

*Corresponding author. Tel: +1-734-763-8436; Fax: +1-734-763-4788

Email: ppoudeup@,umich.edu (PFPP)

‡ Equal contribution

Keywords: Nanostructures $\cdot$ Doped Semiconductor $\cdot$ Half-Heusler $\cdot$ Heusler $\cdot$ Energy filtering 


\begin{abstract}
Energy filtering of charge carriers in a semiconducting matrix using atomically coherent nanostructures can lead to a significant improvement of the thermoelectric figure of merit of the resulting composite. In this work, several half-Heusler/full-Heusler $(\mathrm{HH} / \mathrm{FH})$ nanocomposites with general compositions $\mathrm{Zr}_{0.25} \mathrm{Hf}_{0.75} \mathrm{Ni}_{1+\mathrm{x}} \mathrm{Sn}_{1-\mathrm{y}} \mathrm{Sb}_{\mathrm{y}}(0 \leq \mathrm{x} \leq 0.15$ and $\mathrm{y}=0.005,0.01$ and 0.025$)$ were synthesized in order to investigate the behavior of extrinsic carriers at the $\mathrm{HH} / \mathrm{FH}$ interfaces. Electronic transport data showed that energy filtering of carriers at the HH/FH interfaces in $\mathrm{Zr}_{0.25} \mathrm{Hf}_{0.75} \mathrm{Ni}_{1+\mathrm{x}} \mathrm{Sn}_{1-\mathrm{y}} \mathrm{Sb}_{\mathrm{y}}$ samples strongly depends on the doping level (y value) as well as the energy levels occupied by impurity states in the samples. For example, it was found that carrier filtering at $\mathrm{HH} / \mathrm{FH}$ interfaces is negligible in $\mathrm{Zr}_{0.25} \mathrm{Hf}_{0.75} \mathrm{Ni}_{1+\mathrm{x}} \mathrm{Sn}_{1-\mathrm{y}} \mathrm{Sb}_{\mathrm{y}}(\mathrm{y}=0.01$ and 0.025$)$ composites where donor states originating from $\mathrm{Sb}$ dopant dominate electronic conduction. However, we observed a drastic decrease in the effective carrier density upon introduction of $\mathrm{HH} / \mathrm{FH}$ interfaces for the mechanically alloyed $\mathrm{Zr}_{0.25} \mathrm{Hf}_{0.75} \mathrm{Ni}_{1+\mathrm{x}} \mathrm{Sn}_{0.995} \mathrm{Sb}_{0.005}$ samples where donor states from unintentional Fe impurities contribute the largest fraction of conduction electrons. This work demonstrates the ability to synergistically integrate the concepts of doping and energy filtering through nanostructuring for the optimization of electronic transport in semiconductors.
\end{abstract}




\section{Introduction}

The prospect of manipulating electronic, and phonon transports in bulk semiconductors using embedded nanostructures has generated widespread research interests for the discovery of new physics and the development of multifunctional materials and devices for various important technological applications. For example, in the field of thermal-to-electrical (thermoelectric) energy conversion technology, recent advances in materials development have shown that significant enhancements in the materials thermoelectric figure of merit, $Z \mathrm{~T}=\sigma \mathrm{S}^{2} \mathrm{~T} / \kappa$ (where $\sigma$ is electrical conductivity, $\mathrm{S}$ is the thermopower, $\mathrm{T}$ is the absolute temperature and $\kappa$ is the thermal conductivity) can be realized by integrating, at the atomic scale, suitable secondary phases within a selected promising semiconducting matrix ${ }^{[1-11]}$ These improvements in the figure of merit generally originate from a large suppression of the thermal conductivity which is attributed to enhanced phonon scattering at the matrix/inclusion interfaces within the resulting bulk composites. $^{[1-11]}$ However, recent reports demonstrated that ZT enhancements due to the improvement of the power factor (PF) using nanostructuring, as opposed to the traditional doping strategy, could also be achieved in bulk nanostructured semiconductors. ${ }^{[1,6-14]}$ Improvements in the power factor in such nanocomposites mainly occur when enhancements in the thermopower and/or carrier's mobility can be realized, while avoiding additional doping of the matrix. This implies that the embedded nanostructures should (1) have a high degree of lattice coherency with the matrix in order to minimize reduction in carrier mobility by eliminating scattering of charge carriers during transport across the matrix/inclusion interfaces; (2) have a suitable conduction band $(\mathrm{CB})$ or valence band $(\mathrm{VB})$ energy offset, $\Delta \mathrm{E}$, with the matrix, in order to enable enhancement of the thermopower and overall carrier mobility by trapping or filtering undesirable conducting carriers at the matrix/inclusion interfaces; and (3) be electronically inert with respect to the matrix to avoid dumping additional charge carriers to the existing ensemble of free carriers within the matrix.

Careful consideration of the combination of matrix/inclusion systems investigated so far suggests that for a given semiconducting matrix, the choice of the embedded nanostructures should take into account their structural relationship with the matrix. For instance, it appears that the similarity in the crystallographic arrangement of at least one type of element shared by the matrix and inclusion phases is necessary to facilitate lattice coherency at the phase boundaries as well as to promote band alignment at the matrix/inclusion interfaces. ${ }^{[1-3,6-14]}$ However, it should 
be noted that although structural similarity between matrix and inclusion is a necessary condition for lattice coherency and band alignment, it is not sufficient to ensure improvement of electronic transport at the matrix/inclusion interfaces. For example, while marginal decrease or large enhancement in the carrier mobility was observed in $\mathrm{PbTe} / \mathrm{SrTe},{ }^{[15]} p$-type $\mathrm{Pb} 0.95 \mathrm{Na} 0.025 \mathrm{~S} / \mathrm{CdS},{ }^{[12,13]}$ and $\left(\mathrm{Si}_{95} \mathrm{Ge}_{5}\right)_{0.65}\left(\mathrm{Si}_{70} \mathrm{Ge}_{30} \mathrm{P}_{3}\right)_{0.35}{ }^{[14]}$ bulk composites, embedding metal sulfide (MS) nanocrystals in n-type $\mathrm{PbS}$ resulted in a large reduction in the overall carrier mobility. ${ }^{[1,12,13]}$ This suggests that enhancements in the electronic transport across the matrix/inclusion interfaces in such bulk nanocomposite systems is actually strongly influenced by the height of the energy offset, $\Delta \mathrm{E}$, between the valence band maxima (VBM) or the conduction band minima (CBM) of the matrix and the embedded inclusion. It was found that large $\Delta \mathrm{E}$ increases carrier scattering at the matrix/inclusion interfaces leading to large decrease in the carrier mobility. ${ }^{[12,13]}$ The energy offset, $\Delta \mathrm{E}$, can be engineered further by tuning band alignment through (1) formation of limited solid solutions between the matrix and inclusion phases or between two inclusion phases ${ }^{[1,16]}$, and/or (2) by tuning the average size range and dispersion of the inclusion phases coherently embedded inside the matrix in order to minimize the drop and perhaps even achieve a large enhancement in the overall carrier mobility. ${ }^{[8-10]}$ The observation of an enhancement in the overall carrier mobility upon reducing the height of the offset energy, $\Delta \mathrm{E}$, in some systems, coupled to sharply different behavior of charge carrier's mobility in n-type PbS and p-type PbS containing CdS inclusions ${ }^{[12,13]}$ suggests that for a matrix/inclusion bulk nanocomposites with a given $\Delta \mathrm{E}$, the energy distribution of impurity states (donor or acceptor states contributing the largest fraction of conduction carrier) may play an important role in the observed change in the carrier transport.

Here we attempt to investigate this hypothesis in bulk nanocomposites consisting of a half-Heusler $(\mathrm{HH})$ matrix containing full-Heusler $(\mathrm{FH})$ inclusions. The half-Heusler $(\mathrm{HH})$ alloys represent a fascinating large class of intermetallic phases with general composition TMX (T and $\mathrm{M}$ are transition metal or rare-earth metals and $\mathrm{X}$ is a main-group element) that crystallize in the MgAgAs structure type (space group: F-43m). Their crystal structure formed by fcc (facecentered cubic) sublattices of $T, M$ and $X$ atoms contains the tetrahedral vacant site $(3 / 4,3 / 4$, $3 / 4),{ }^{[17,18]}$ which can accommodate additional $\mathrm{M}$ atoms to generate the related ternary fullHeusler (FH) phase with general composition $\mathrm{TM}_{2} \mathrm{X}$, crystallizing in the centrosymmetric cubic $\mathrm{MnCu}_{2} \mathrm{Al}$ structure-type (SG: Fm-3m). ${ }^{[10,19-22]}$ This close structural relationship between $\mathrm{HH}$ and 
FH phases facilitates band alignment and coherent phase boundaries at the $\mathrm{HH} / \mathrm{FH}$ interfaces in bulk $\mathrm{HH}(1-\mathrm{x}) / \mathrm{FH}(\mathrm{x})$ nanocomposites. Half-Heusler $(\mathrm{HH})$ compounds and related composites have attracted tremendous attention as potential candidates for thermoelectrics, ${ }^{[10,11,23-40]}$ halfmetallic dilute magnetic semiconductors (spintronics), ${ }^{[41-44]}$ and as topological insulators. ${ }^{[45-47]}$ Recently, we demonstrated the ability to coherently integrate atomic-scale nanoinclusions with a FH structure into a bulk matrix with a $\mathrm{HH}$ structure to form $\mathrm{HH}\left((1-\mathrm{x}) / \mathrm{FH}(\mathrm{x})\right.$ nanocomposites. ${ }^{[6-11]}$ We observed that in undoped or poorly doped $n$-type systems, $(\mathrm{Zr}, \mathrm{Hf}) \mathrm{Ni}_{1+\mathrm{x}} \mathrm{Sn}$ and $(\mathrm{Ti}, \mathrm{Zr}) \mathrm{Ni}_{1+\mathrm{x}} \mathrm{Sn}$ and the p-type system (Ti,Zr)Co ${ }_{1+z} \mathrm{Sb}$, large enhancements in the thermopower and carrier mobility are possible for optimum size and concentration of the FH inclusions. ${ }^{[6-11]}$ We suggested using electron microscopy and electronic and thermal transport data, that the simultaneous enhancement of both charge carrier mobility and thermopower in various $\mathrm{HH} / \mathrm{FH}$ nanocomposites with a large reduction in the thermal conductivity results from the formation of a potential barrier, $\Delta \mathrm{E}$, at the $\mathrm{HH} / \mathrm{FH}$ coherent nanointerfaces, which act as energy filter, trapping low energy carriers while 'promoting the transfer of high energy carriers across the $\mathrm{HH} / \mathrm{FH}$ interfaces. ${ }^{[6-11]}$ However, we observed that for heavily doped $\mathrm{FH} / \mathrm{HH}$ composites, the magnitude of the energy filtering effect, which is manifested by a large reduction in the effective carrier density (low energy carriers are trapped at the interfaces) and a large increase in both the thermopower and carrier mobility, depends on the type of dopants. For example, a strong energyfiltering effect (for the sample with an excess of $6 \% \mathrm{FH}$ inclusions, the carrier density at $300 \mathrm{~K}$ dropped from $8 \times 10^{19}$ to $5 \times 10^{19} \mathrm{~cm}^{-3}$ while the thermopower increased from -140 to $-230 \mu \mathrm{V} / \mathrm{K}$ and the carrier mobility increased from 20 to $50 \mathrm{~cm}^{2} / \mathrm{V} \cdot \mathrm{S}$ ) was observed in the Bi-doped HH/FH nanocomposites, $\mathrm{Zr}_{0.25} \mathrm{Hf}_{0.75} \mathrm{Ni}_{1+\times} \mathrm{Sn}_{0.975} \mathrm{Bi}_{0.025},{ }^{[10]}$ whereas virtually no energy filtering effect (the carrier density, thermopower and carrier mobility, remained unchanged upon introduction of the FH phase in the HH matrix) was observed in the Sb-doped counterpart, with a similar doping level, Ti0.1 $\mathrm{Zr}_{0.9 \mathrm{Ni} 1+\mathrm{x} \text { Sn0.975Sb0.025. }}{ }^{[6]}$

To probe the role of the density and energy distribution of impurity states on the magnitude of energy filtering effect at the $\mathrm{HH} / \mathrm{FH}$ interfaces in bulk $\mathrm{HH}(1-\mathrm{x}) / \mathrm{FH}(\mathrm{x})$ nanocomposites, several nanocomposites with general compositions $\mathrm{Zr}_{0.25} \mathrm{Hf}_{0.75} \mathrm{Ni}_{1+\mathrm{x}} \mathrm{Sn}_{1-\mathrm{y}} \mathrm{Sb}_{\mathrm{y}}(0$ $\leq \mathrm{x} \leq 0.15 ; \mathrm{y}=0.005,0.01,0.025)$ containing various density and type of extrinsic carriers were synthesized by reacting elemental powders via solid-state reaction at high temperature followed by mechanical alloying of a portion of the synthesized materials using high energy shaker mill. 
The synthesized composites were structurally characterized using X-ray diffraction (XRD) and transmission electron microscopy (TEM), and their electronic transport properties were investigated. We found that starting from $\mathrm{HH}$ matrices containing equal volume fraction of $\mathrm{FH}$ nanoinclusions (constant $\mathrm{x}$ value) with similar average size range, the magnitude of energy filtering of charge carriers by the potential energy barrier at the $\mathrm{HH} / \mathrm{FH}$ interfaces strongly depends on the energy distribution of impurity states (donor or acceptor states) within the band gap of the HH matrix as well as the relative density of extrinsic carriers compared to intrinsic carriers participating to electronic transport. For instance, no energy-filtering effect was observed in $\mathrm{Zr}_{0.25} \mathrm{Hf}_{0.75} \mathrm{Ni}_{1+\mathrm{x}} \mathrm{Sn}_{1-\mathrm{y}} \mathrm{Sb}_{\mathrm{y}}$ samples in which donor states from doping through $\mathrm{Sb}$ substitutions at Sn sites and from doping by large metallic FH inclusions ( $y=0.01$ and 0.025$)$ dominate electronic conduction. However, a very strong energy filtering effect was observed for the mechanically alloyed $\mathrm{Zr}_{0.25} \mathrm{Hf}_{0.75} \mathrm{Ni}_{1+\times} \mathrm{Sn}_{0.995} \mathrm{Sb}_{0.005}$ samples in which donor states from unintentional impurities, such as Fe, dominate electronic transport. This work demonstrates that the potential energy barrier at $\mathrm{HH} / \mathrm{FH}$ interfaces can be exploited to discriminate and decouple dopants with various energy levels doped HH semiconductors. Therefore, the optimization of the thermoelectric properties of semiconductors through synergistic integration of the concepts of doping and energy filtering using nanostructuring requires a good match between (1) the type of doping element (energy level occupied by impurity states) and (2) the average size and distribution (the heights of the potential energy barrier) of the nanostructures coherently embedded inside the semiconducting matrix. 


\section{Experimental}

Synthesis. Sb-doped half-Heusler/full-Heusler (HH/FH) nanocomposites with general composition $\mathrm{Zr}_{0.25} \mathrm{Hf}_{0.75} \mathrm{Ni}_{1+\mathrm{x}} \mathrm{Sn}_{1-\mathrm{y}} \mathrm{Sb}_{\mathrm{y}}(\mathrm{y}=0.025,0.01$ and 0.005$)$ were synthesized by solid-state reaction of high purity elemental powders in stoichiometric amount. Desired ratio powders were thoroughly ground using an agate mortar and pestle under Ar atmosphere. The mixed powders were sealed into a quartz tube under a residual pressure of $10^{-3}$ Torr and subsequently heated to $673 \mathrm{~K}$ for $4 \mathrm{~h}$ and to $1173 \mathrm{~K}$ for $300 \mathrm{~h}$. The resulting polycrystalline powders of $\mathrm{Zr}_{0.25} \mathrm{Hf}_{0.75} \mathrm{Ni}_{1+\mathrm{x}} \mathrm{Sn}_{1-\mathrm{y}} \mathrm{Sb}_{\mathrm{y}}$ samples with $\mathrm{y}=0.025,0.01$ were consolidated into high-density pellets without further processing, whereas samples with $\mathrm{y}=0.005$ were subjected to mechanical alloying before consolidation. The milling experiments were performed using a high-energy shaker ball mill apparatus (Spex 8000D Dual Mixer/Mill). The annealed powders of the $\mathrm{Zr}_{0.25} \mathrm{Hf}_{0.75} \mathrm{Ni}_{1+\mathrm{x}} \mathrm{Sn}_{0.995} \mathrm{Sb}_{0.005}$ samples were loaded, under argon atmosphere inside a glove box, into hardened steel jars along with hardened steel balls. A ball to powder mass ratio of 5:1 was maintained and samples were milled for $10 \mathrm{~h}$. As discussed below, the mechanical alloying step resulted in the introduction of small fraction of $\mathrm{Fe}$ impurities into the $\mathrm{Zr}_{0.25} \mathrm{Hf}_{0.75} \mathrm{Ni}_{1+\mathrm{x}} \mathrm{Sn}_{0.995} \mathrm{Sb}_{0.005}$ samples. All $\mathrm{Zr}_{0.25} \mathrm{Hf}_{0.75} \mathrm{Ni}_{1+\mathrm{x}} \mathrm{Sn}_{1-\mathrm{y}} \mathrm{Sb}_{\mathrm{y}}$ were consolidated into pellets at $1223 \mathrm{~K}$ under $60 \mathrm{MPa}$ using spark plasma sintering (SPS). Additional details on the densification procedures are described elsewhere ${ }^{[10,11]}$. The relative packing densities for all pellets with respect to the density of the loose powders were above $98 \%$.

Characterization. The structure and phase purity of the as-prepared powders were investigated using powder X-ray diffraction (PXRD) on a rotating anode Rigaku powder diffractometer operating at $40 \mathrm{kV}$ and $100 \mathrm{~mA}$ through monochromated $\mathrm{Cu} \mathrm{K} \alpha$ radiation. In order to probe the presence or absence of trace amount impurities in the $\mathrm{Zr}_{0.25} \mathrm{Hf}_{0.75} \mathrm{Ni}_{1+\mathrm{x}} \mathrm{Sn}_{0.995} \mathrm{Sb}_{0.005}$ samples processed by mechanical alloying, their chemical compositions of were characterized by wavelength dispersive X-ray fluorescence spectroscopy. The internal structure of selected samples was observed by a high-resolution transmission electron microscope (HRTEM, JEOL 3011). Thermopower and electrical resistivity were measured simultaneously from room temperature to $773 \mathrm{~K}$ under a low pressure He atmosphere using a commercial ZEM-3 system from ULVAC-RIKO. The instrument precision in the thermopower and electrical resistivity is \pm $4 \%$. The thermal conductivity was calculated from thermal diffusivity measured using the laser 
flash method (LFA-1000 from Linseis) from $293 \mathrm{~K}$ to $773 \mathrm{~K}$ under dynamic vacuum. The instrument precision in the thermal diffusivity data is $\pm 3 \%$. The Hall effect coefficient data were measured in the temperature range from $300 \mathrm{~K}$ to $775 \mathrm{~K}$ under a magnetic field of $1 \mathrm{~T}$ using a large Oxford air-borne superconducting magnet cryostat that accommodates a small tubular oven and a Hall insert. The instrument uncertainty in Hall coefficient data is $\pm 5 \%$. The electrical conductivity data were combined with the Hall coefficient measurement to evaluate and extract accurate information on the temperature dependence of the carrier concentration and the mobility of the charge carriers in the nanocomposites.

\section{Result and Discussion}

\section{Synthesis and characterization}

Powder X-ray diffraction patterns of the assynthesized $\quad \mathrm{Zr}_{0.25} \mathrm{Hf}_{0.75} \mathrm{Ni}_{1+\mathrm{x}} \mathrm{Sn}_{1-\mathrm{y}} \mathrm{Sb}_{\mathrm{y}} \quad \mathrm{FH} / \mathrm{HH}$ composites are shown in Figure 1. Samples with $\mathrm{y}=0.005,0.01$ and 0.025 were synthesized through solid-state reaction of high purity elemental powders. Samples with $\mathrm{y}=0.005$ were further processed via mechanical alloying using high-energy shaker ball milling. Regardless of the synthesis and processing methods, all peaks on the XRD patterns can be indexed in the cubic MgAgAs-type structure suggesting the formation of single-phase $\mathrm{HH}$
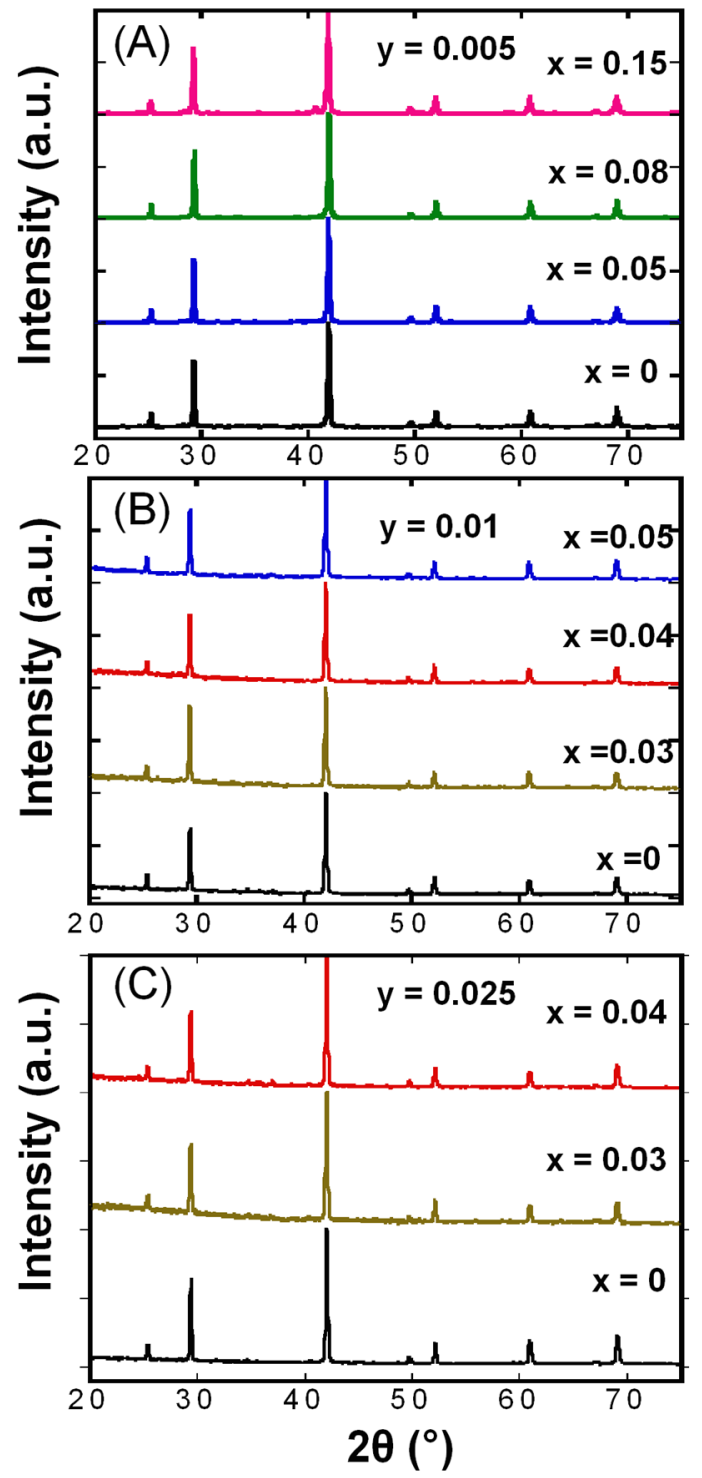

Figure 1: Powder XRD pattern of the synthesized composites for $\mathrm{Zr}_{0.25} \mathrm{Hf}_{0.75} \mathrm{Ni}_{1+\mathrm{x}} \mathrm{Sn}_{1 \text { - }}$ ${ }_{\mathrm{y}} \mathrm{Sb}_{\mathrm{y}}$ composites. alloys. Interestingly, the addition of excess $\mathrm{Ni}$ in various $\mathrm{HH}$ matrices does not create additional diffraction peaks on the XRD patterns that could be assigned to the formation of FH phase in the samples as would be anticipated from the chemical equation (1). 
$0.25 \mathrm{Zr}+0.75 \mathrm{Hf}+(1+\mathrm{x}) \mathrm{Ni}+(1-\mathrm{y}) \mathrm{Sn}+\mathrm{y} \mathrm{Sb} \rightarrow(1-\mathrm{x}) \mathrm{Zr}_{0.25} \mathrm{Hf}_{0.75} \mathrm{NiSn}_{1-\mathrm{y}} \mathrm{Sb}_{\mathrm{y}}(\mathrm{HH})+\mathrm{x}$

$\mathrm{Zr}_{0.25} \mathrm{Hf}_{0.75} \mathrm{Ni}_{2} \mathrm{Sn}_{1-\mathrm{y}} \mathrm{Sb}_{\mathrm{y}}(\mathrm{FH})$

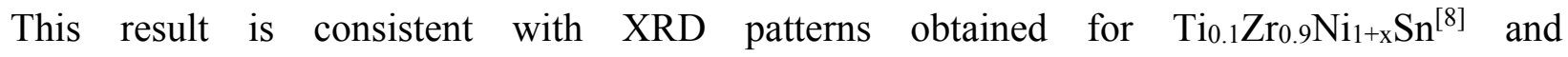
$\mathrm{Zr}_{0.25} \mathrm{Hf}_{0.75} \mathrm{Ni}_{1+\times} \mathrm{Sn}^{[10]}$ $\mathrm{HH} / \mathrm{FH}$

nanocomposites and either suggests that the size of $\mathrm{FH}$ phase in $\mathrm{Zr}_{0.25} \mathrm{Hf}_{0.75} \mathrm{Ni}_{1+\times} \mathrm{Sn}_{1-}$ ${ }_{y} \mathrm{Sb}_{\mathrm{y}}$ is too small to diffract X-ray or that impurities arising from the use of excess $\mathrm{Ni}$ are soluble in the HH matrix. However, our recent careful theoretical investigation of the dissolution of $\mathrm{Ni}$ in the MNiSn (HH) and $\mathrm{MNi}_{2} \mathrm{Sn}(\mathrm{FH})$ phases $(\mathrm{M}=\mathrm{Ti}, \mathrm{Zr}, \mathrm{Hf})$ revealed negligible Ni solubility in either phase up to approximately $1000 \mathrm{~K}$ and a spontaneous precipitation of the $\mathrm{FH}$ phase upon addition of excess $\mathrm{Ni}$ into the vacant sites of the $\mathrm{HH}$ structure. ${ }^{[48]}$ This theoretical prediction of negligible $\mathrm{Ni}$ solubility in the HH matrix is supported by the constant value of unit cell parameter, $a$ $=6.15$ (8) $\AA$, of various $\mathrm{Zr}_{0.25} \mathrm{Hf}_{0.75} \mathrm{Ni}_{1+\times} \mathrm{Sn}_{1-}$ ySby samples regardless of the amount of excess $\mathrm{Ni}$ and/or $\mathrm{Sb}$ doping level. It can be derived from the above analysis that the structure and composition of the $\mathrm{HH}$ matrix remains unchanged upon addition of excess Ni element and that the added

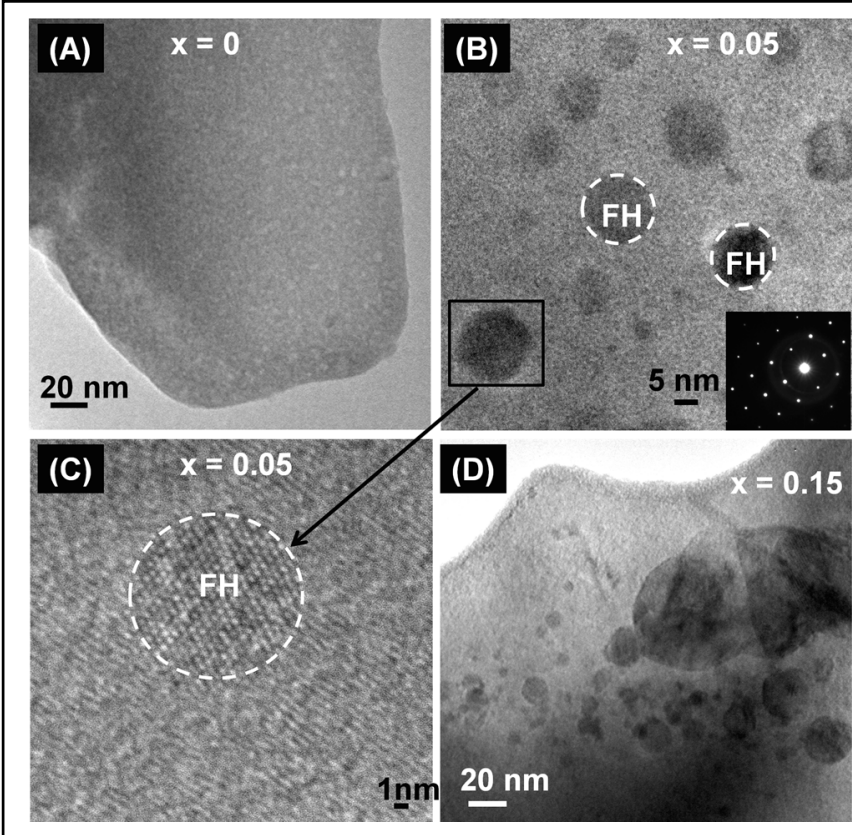

Figure 2: Structural characteristics of $\mathrm{Zr}_{0.25} \mathrm{Hf}_{0.75} \mathrm{Ni}_{1+\times} \mathrm{Sn}_{0.995} \mathrm{Sb}_{0.005}$ nanocomposites. (A) Low magnification TEM image of the $\mathrm{HH}$ matrix, revealing the matrix is clear and no inclusion or impurities. (B) Medium magnification TEM image of the sample with $\mathrm{x}=$ 0.05 showing $\mathrm{FH}$ particles with size range from $5 \mathrm{~nm}$ to $20 \mathrm{~nm}$ coherently embedded inside the $\mathrm{HH}$ matrix and selected-area electron diffraction pattern (inset of B) indicating the fcc structure of the HH matrix. (C) High magnification TEM image of selected $\mathrm{FH}$ particle from the sample with $\mathrm{x}=0.05$, showing nearly spherical $\mathrm{FH}$ nanoinclusion lattice details. (D) Low magnification TEM image of the sample with $\mathrm{x}=$ 0.15 , showing high agglomeration of $\mathrm{FH}$ nanophase into large particle.

excess $\mathrm{Ni}$ induced the formation of equivalent mole fraction of $\mathrm{FH}$ precipitates, accordingly with chemical equation (1), within the HH matrix.

To probe the internal structure of the synthesized $\mathrm{Zr}_{0.25} \mathrm{Hf}_{0.75} \mathrm{Ni}_{1+x} \mathrm{Sn}_{1-\mathrm{y}} \mathrm{Sb}_{\mathrm{y}}$, high resolution transmission electron microscopy (HRTEM) images were collected on selected 
samples. Figure 2 shows HRTEM images highlighting microstructural characteristics of selected $\mathrm{Zr}_{0.25} \mathrm{Hf}_{0.75} \mathrm{Ni}_{1+\times} \mathrm{Sn}_{0.995} \mathrm{Sb}_{0.005}$ nanocomposites. At low magnification the TEM image of the HH matrix (Figure 2A) suggests the formation of single-phase HH structure. No inclusion or impurities phases are found on the TEM image. However, the addition of excess elemental $\mathrm{Ni}$ into the $\mathrm{HH}$ matrix leads to the formation of small dark precipitates (Figure 2B and 2D). These nanoinclusions are believed to adopt $\mathrm{FH}$ structure and composition given the high degree of coherency with the HH matrix (Figure 2C). As can be observed from the TEM images of the sample with $x=0.05, y=0.005$, the $\mathrm{FH}$ nanoprecipitates formed as small spherical particles with size ranging from $5 \mathrm{~nm}$ to $20 \mathrm{~nm}$ (Figure 2B). Increasing the concentration of excess Ni resulted in the formation of a larger fraction of $\mathrm{FH}$ precipitates. Some precipitates agglomerate into large nanoparticles with size of up to $100 \mathrm{~nm}$ as can be observed on the TEM image of

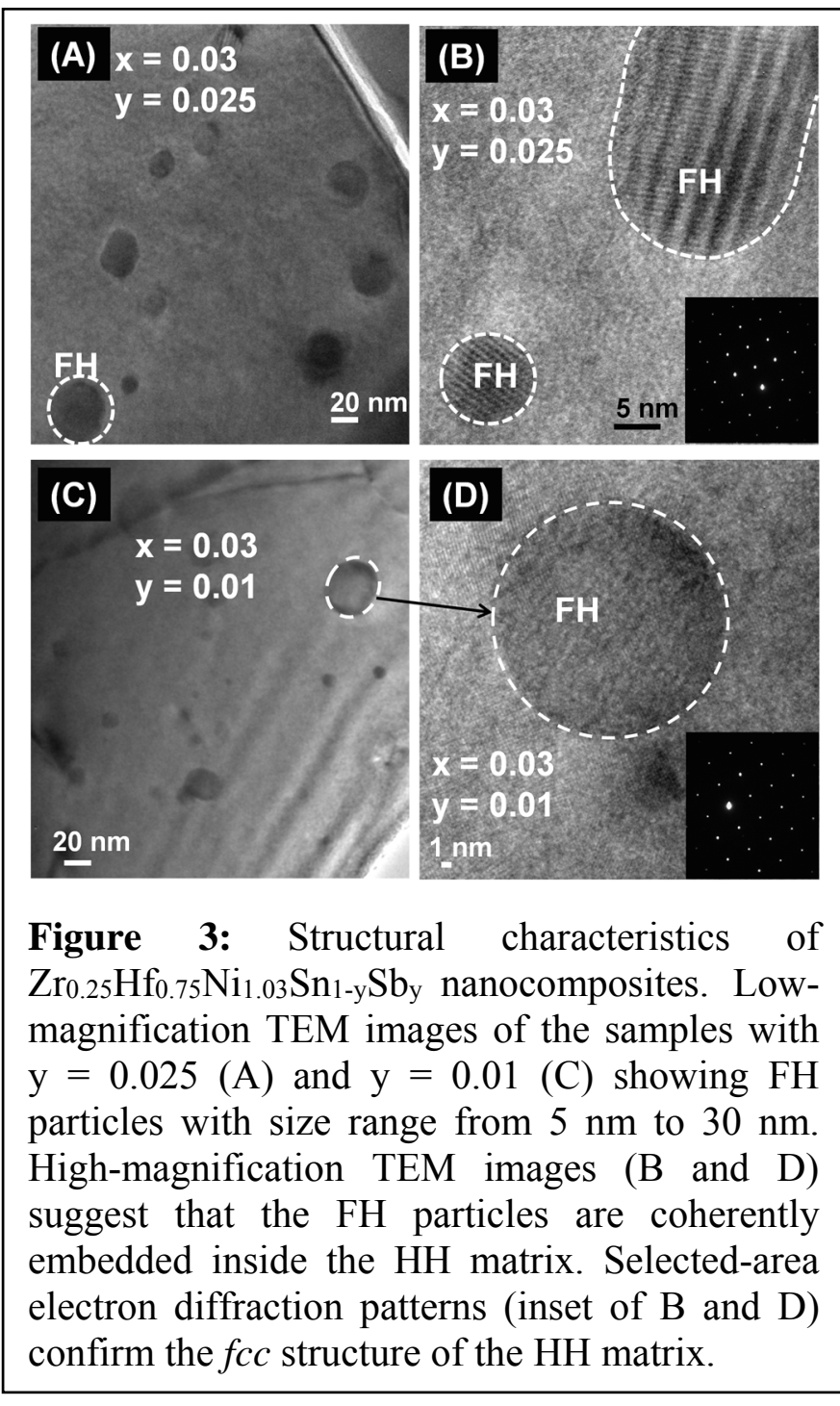

$\mathrm{Zr}_{0.25} \mathrm{Hf}_{0.75} \mathrm{Ni}_{1.15} \mathrm{Sn} 0.995 \mathrm{Sb} 0.005$ (Figure 2D). Similar microstructural characteristics are observed in $\mathrm{Zr}_{0.25} \mathrm{Hf}_{0.75} \mathrm{Ni}_{1+\mathrm{x}} \mathrm{Sn}_{0.975} \mathrm{Sb}_{0.025}$ and $\mathrm{Zr}_{0.25} \mathrm{Hf}_{0.75} \mathrm{Ni}_{1+\times} \mathrm{Sn}_{0.99} \mathrm{Sb}_{0.01}$ samples. Figure 3 shows TEM images of $\mathrm{Zr}_{0.25} \mathrm{Hf}_{0.75} \mathrm{Ni}_{1.03} \mathrm{Sn}_{1-\mathrm{y}} \mathrm{Sb}_{\mathrm{y}}$ samples with $\mathrm{y}=0.025$ and $\mathrm{y}=0.01$. Both samples contain similar volume fraction of FH inclusions $(\mathrm{x}=0.03)$ with particle size in the range from $5 \mathrm{~nm}$ to $30 \mathrm{~nm}$. This indicates that tuning the amount of excess elemental $\mathrm{Ni}$ in the starting mixture can indirectly control the volume fraction, and size distribution of FH particles within the $\mathrm{HH}$ matrix, under a given synthesis condition. From the above analysis of the microstructures of $\mathrm{Zr}_{0.25} \mathrm{Hf}_{0.75} \mathrm{Ni}_{1+x} \mathrm{Sn}_{1-\mathrm{y}} \mathrm{Sb}_{\mathrm{y}}$ composites, one can conclude that regardless of the doping level (y 
value), increasing the amount of excess elemental $\mathrm{Ni}$ ( $\mathrm{x}$ value) in the $\mathrm{HH}$ matrix results in an increase in the volume fraction and the average particle size of the FH nanoinclusions. This is due to the fact that the increase in the population density of small FH nanoinclusions facilitates coarsening through aggregation of nanoparticles in close proximity. The presence of both small and large $\mathrm{FH}$ nanoinclusions in $\mathrm{Zr}_{0.25} \mathrm{Hf}_{0.75} \mathrm{Ni}_{1+\mathrm{x}} \mathrm{Sn}_{1-\mathrm{y}} \mathrm{Sb}_{\mathrm{y}}$ composites with high $\mathrm{x}$ values is expected to significantly alter their electronic and phonon transports. While FH nanoinclusions with size below $10 \mathrm{~nm}$ are believed to be semiconducting, ${ }^{[8-10]}$ larger $\mathrm{FH}$ inclusions behave as metals, contributing additional charge carriers to the HH matrix. ${ }^{[11]}$ Interestingly, the analysis of the chemical composition of $\mathrm{Zr}_{0.25} \mathrm{Hf}_{0.75} \mathrm{Ni}_{1+} \mathrm{Sn}_{0.995} \mathrm{Sb}_{0.005}$ samples, processed by mechanical alloying using wavelength dispersive X-ray fluorescence spectroscopy revealed the presence of 1.8 to 2 at.\% $\mathrm{Fe}$ in samples with various $\mathrm{x}$ values. This suggests that electronic properties in this series of samples will be affected by contribution from these impurities. However, it is not clear whether the Fe impurities substitute for $\mathrm{Ni}$ in the crystal structure of the $\mathrm{HH}$ matrix or enter vacant sites to form Fe-containing FH particles. However, the absence of FH particles in the $\mathrm{Zr}_{0.25} \mathrm{Hf}_{0.75} \mathrm{NiSn}_{0.995} \mathrm{Sb}_{0.005}$ sample $(\mathrm{x}=0 ; \mathrm{y}=0.005)$ processed by mechanical alloying suggests that the Fe impurities served as dopants in the HH matrix, presumably partially filling structural vacant sites. Likewise, Fe impurities in $\mathrm{Zr}_{0.25} \mathrm{Hf}_{0.75} \mathrm{Ni}_{1+{ }_{\mathrm{x}}} \mathrm{Sn}_{0.995} \mathrm{Sb}_{0.005}$ samples are probably located into vacant sites within the HH matrix since the mechanical alloying procedure leading to the introduction of Fe impurities is preformed on $\mathrm{HH} / \mathrm{FH}$ composite samples. This is due to the fact that in such samples the energy required for the substitution between $\mathrm{Ni}$ and $\mathrm{Fe}$ in $\mathrm{FH}$ structure is larger than the energy associated with the diffusion of Fe impurities within vacant sites in the HH matrix.

\section{Thermoelectric properties}

To investigate the effect of FH inclusions with various volume fraction and average particle size on the electronic and thermal transports of $\mathrm{Zr}_{0.25} \mathrm{Hf}_{0.75} \mathrm{Ni}_{1+\mathrm{x}} \mathrm{Sn}_{1-\mathrm{y}} \mathrm{Sb}_{\mathrm{y}}$ composites, thermopower, electrical conductivity, thermal conductivity and high temperature Hall effect were performed on selected samples. Figure $4 \mathrm{~A}$ and $4 \mathrm{~B}$ show the temperature dependence of the electrical conductivity and thermopower for $\mathrm{Zr}_{0.25} \mathrm{Hf}_{0.75} \mathrm{Ni}_{1+\mathrm{x}} \mathrm{Sn}_{0.975} \mathrm{Sb}_{0.025} \mathrm{FH} / \mathrm{HH}$ composites. In the temperature range $300 \mathrm{~K}$ to $775 \mathrm{~K}$, the electrical conductivity decreases with increasing temperature, which is consistent with heavily doped semiconducting behavior. Regardless of the 
temperature, the electrical conductivity increases with increasing $\mathrm{Ni}$ concentration. At $300 \mathrm{~K}$, the electrical conductivity for the matrix $(\mathrm{x}=0)$ is $\sim 3500 \mathrm{~S} / \mathrm{cm}$ for the sample with $\mathrm{x}=0$ and increases to $3800 \mathrm{~S} / \mathrm{cm}$ for samples with $\mathrm{x}=0.03$ and 0.04 . The observed room temperature value of the electrical conductivities for the $2.5 \% \mathrm{Sb}$-doped samples are 20 times larger than that of the undoped matrix $(\mathrm{y}=0)$ (Figure $5 \mathrm{~A}) \cdot{ }^{[11]}$ This suggests that $\mathrm{Sb}$ substitution at $\mathrm{Sn}$ sites
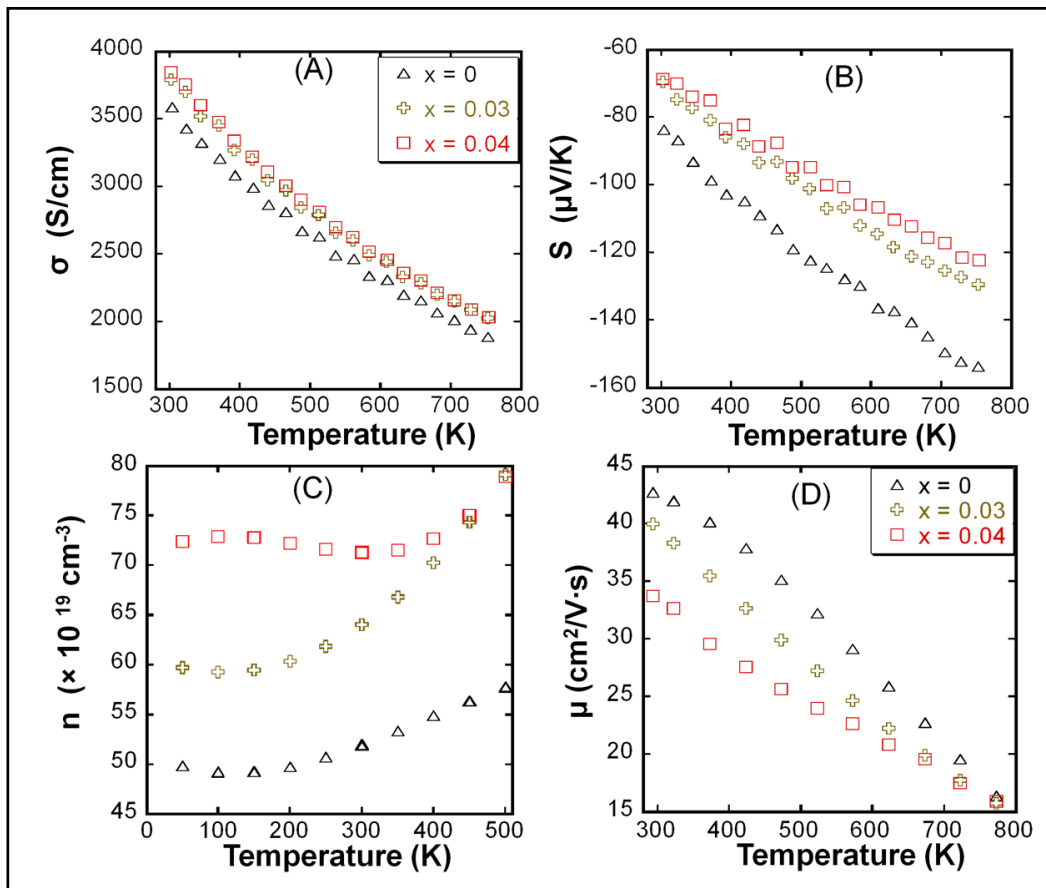

Figure 4: Temperature dependence of (A) electrical conductivity; (B) thermopower; (C) carrier concentration; and (D) mobility for $\mathrm{Zr}_{0.25} \mathrm{Hf}_{0.75} \mathrm{Ni}_{1+\mathrm{x}} \mathrm{Sn}_{0.975} \mathrm{Sb}_{0.025}$. drastically increase the overall carrier density. Upon increasing the temperature, the electrical conductivity of $\mathrm{Zr}_{0.25} \mathrm{Hf}_{0.75} \mathrm{Ni}_{1+\mathrm{x}} \mathrm{Sn}_{0.975} \mathrm{Sb}_{0.025}$ decreases, reaching $\sim 1800$ $\mathrm{S} / \mathrm{cm}(\mathrm{x}=0)$ and $2000 \mathrm{~S} / \mathrm{cm}(\mathrm{x}$ $=0.03$ and 0.04 ) at $775 \mathrm{~K}$. Regardless of the temperature, the electrical conductivity of $\mathrm{Zr}_{0.25} \mathrm{Hf}_{0.75} \mathrm{Ni}_{1+x} \mathrm{Sn}_{0.975} \mathrm{Sb}_{0.025}$ samples slightly increase with increasing $\mathrm{x}$ values, suggesting a marginal doping of the $\mathrm{HH}$ matrix by the embedded $\mathrm{FH}$ inclusions.

All samples exhibit negative values of the thermopower (Figure 4B) in the measured temperature range indicating $n$ type semiconducting behavior. Within this temperature range, the thermopower for all samples increases almost linearly with increasing temperature, which is also consisting with the heavily doped semiconducting behavior. Regardless of the temperature, the thermopower decreases with increasing Ni concentration. At $300 \mathrm{~K}$, the thermopower of the $\mathrm{HH}$ matrix $(\mathrm{x}=0, \mathrm{y}=0.025)$ is $80 \mu \mathrm{V} / \mathrm{K}$ and increases to $-160 \mu \mathrm{V} / \mathrm{K}$ at $775 \mathrm{~K}$. The observed room temperature value of the thermopower of the $2.5 \% \mathrm{Sb}$-doped matrix sample is $\sim 47 \%$ smaller than that of the undoped matrix (Figure 5B), which is consistent with a large increase in the carrier density via Sb substitution at $\mathrm{Sn}$ sites in the $\mathrm{Zr}_{0.25} \mathrm{Hf}_{0.75} \mathrm{NiSn}_{0.975} \mathrm{Sb}_{0.025}$ matrix. Upon increasing the $\mathrm{FH}$ content 
(Ni concentration) to $\mathrm{x}=0.03$ and 0.04 , the thermopower drops to $\sim-70 \mu \mathrm{V} / \mathrm{K}$ at $300 \mathrm{~K}$. However, the thermopower of samples with $\mathrm{x}=0.03$ and 0.04 increases to $-125 \mu \mathrm{V} / \mathrm{K}$ and $-110 \mu \mathrm{V} / \mathrm{K}$, respectively, at $775 \mathrm{~K}$. The observed marginal difference in the thermopower of samples with $\mathrm{x}=$ 0.03 and 0.04 is surprising given the similarity in their electrical conductivity. To better understand the nature of electronic transport in $\mathrm{Zr}_{0.25} \mathrm{Hf}_{0.75} \mathrm{Ni}_{1+} \mathrm{Sn}_{0.975} \mathrm{Sb}_{0.025}$, Hall effect data were collected in the temperature range from $300 \mathrm{~K}$ to $775 \mathrm{~K}$.

Figure 4C and 4D show the temperature dependence of the carrier density and mobility for $\mathrm{Zr}_{0.25} \mathrm{Hf}_{0.75} \mathrm{Ni}_{1+x} \mathrm{Sn}_{0.975} \mathrm{Sb}_{0.025} \mathrm{FH} / \mathrm{HH}$ composites extracted from Hall effect and electrical conductivity data. Regardless of the temperature, the carrier density increases with the $\mathrm{FH}$ content (excess Ni concentration). At $300 \mathrm{~K}$, the carrier density is $50 \times 10^{19} \mathrm{~cm}^{-3}$ for the $2.5 \% \mathrm{Sb}$ -
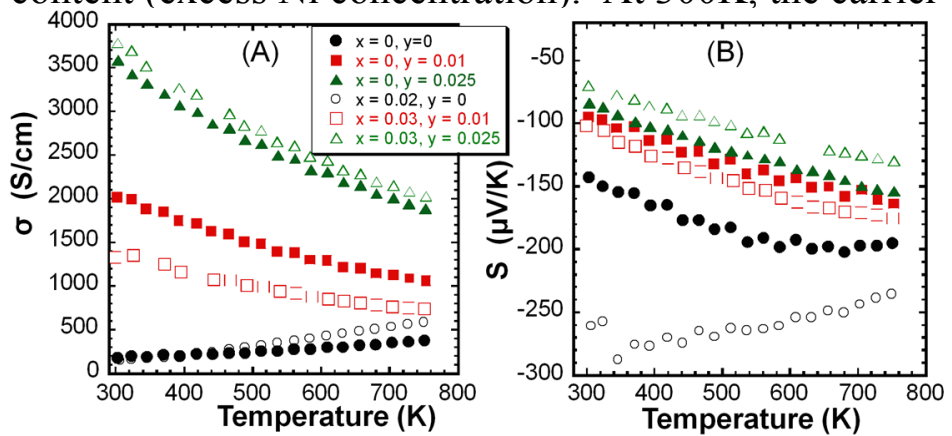

doped matrix $(\mathrm{x}=0)$. The measured value of the carrier density is 5 times larger than the value observed in undoped HH matrix with similar composition (Figure 5C) and is also consistent with the addition of
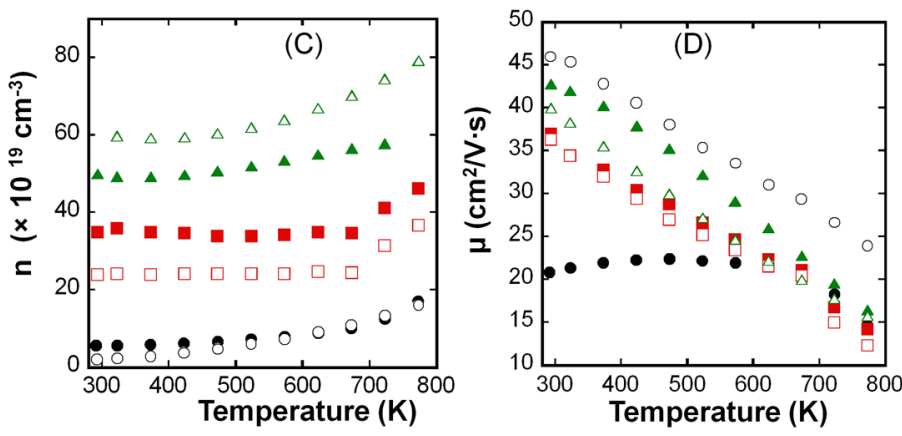
$4.5 \times 10^{19}$ carriers per $\mathrm{cm}^{3}$ expected from the substitution of $0.025 \mathrm{Sn}$ by $\mathrm{Sb}$ in $\mathrm{Zr}_{0.25} \mathrm{Hf}_{0.75} \mathrm{NiSn}^{[10]}$ Upon introduction of $\mathrm{FH}$ inclusions (addition of excess $\mathrm{Ni}$ ), the carrier density increases to $60 \times 10^{19} \mathrm{~cm}^{-3}$ for

Figure 5: Comparison of electronic transports in the sample with $\mathrm{x}=0.03$ and to $\mathrm{Zr}_{0.25} \mathrm{Hf}_{0.75} \mathrm{Ni}_{1+\mathrm{x}} \mathrm{Sn}_{1-\mathrm{y}} \mathrm{Sb}_{\mathrm{y}}$ with various doping levels $\left(\mathrm{y}=0,{ }_{73} \times 10^{19} \mathrm{~cm}^{-3}\right.$ for the sample with $\mathrm{x}=$
0.01 and 0.025$)$.

0.04. This additional increase in the carrier density with $\mathrm{FH}$ content suggests the formation in the $2.5 \% \mathrm{Sb}$-doped $\mathrm{HH}$ matrix of large metallic FH nanoparticles, which contribute carriers to the matrix. Interestingly, the carrier density initially remains temperature independent up to a critical temperature above which an increase in the carrier density with temperature is observed. This onset temperature of thermally activated carriers increases with increasing FH content from $373 \mathrm{~K}(\mathrm{x}=0)$ to $423 \mathrm{~K}(\mathrm{x}=0.03)$ and $623 \mathrm{~K}(\mathrm{x}=0.04)$. 
At $775 \mathrm{~K}$, the carrier density is $57 \times 10^{19} \mathrm{~cm}^{-3}$ for the HH matrix $(\mathrm{x}=0)$ and $\sim 80 \times 10^{19} \mathrm{~cm}^{-}$ 3 for the samples with $\mathrm{x}=0.03$ and 0.04 . The increased carrier density with excess $\mathrm{Ni}$ concentration (FH content) is consistent with the change observed in the electrical conductivity and Seebeck coefficient confirming that the embedded FH phases are metallic in character and contribute additional charge carriers to the $2.5 \%$ Sb-doped $\mathrm{HH}$ matrix. Similar behavior was
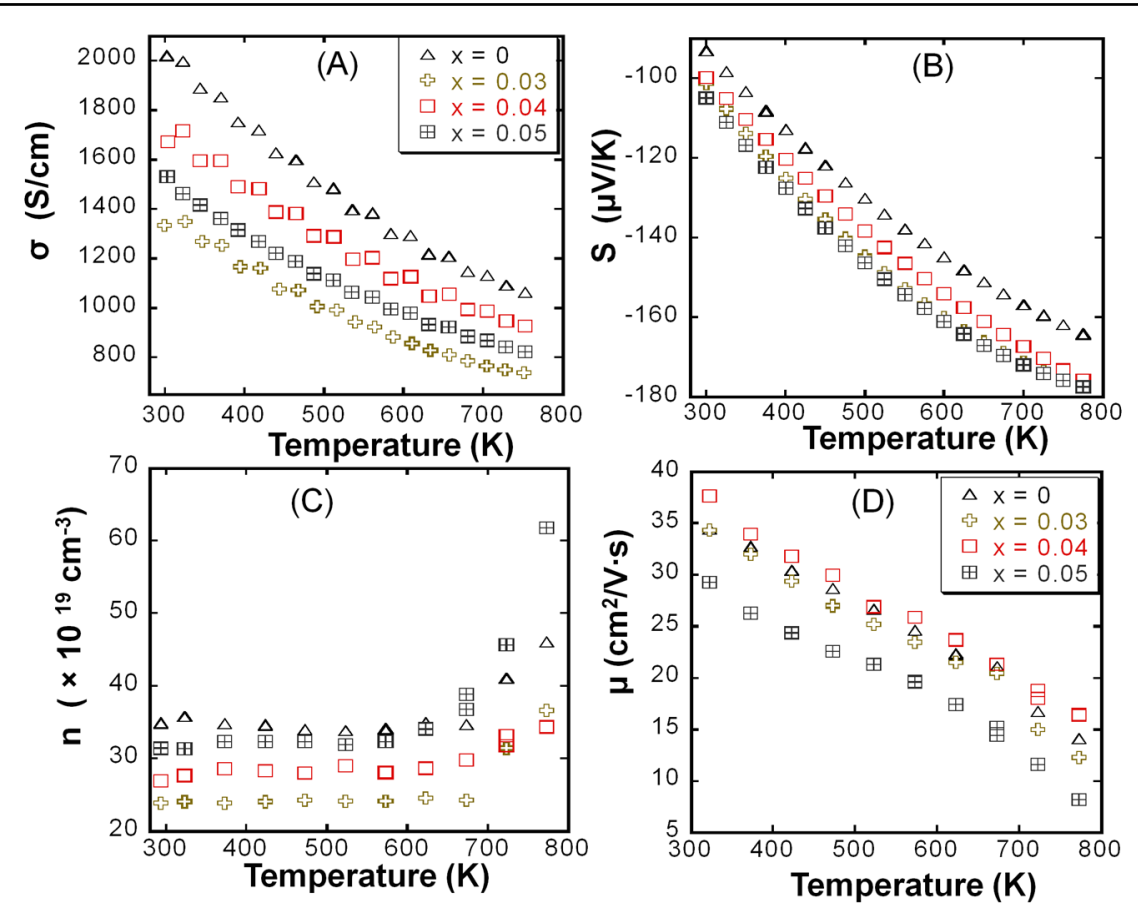

Figure 6: Temperature dependence of (A) electrical conductivity; (B) Thermopower; (C) carrier concentration; and (D) mobility for $\mathrm{Zr}_{0.25} \mathrm{Hf}_{0.75} \mathrm{Ni}_{1+\mathrm{x}} \mathrm{Sn}_{0.99} \mathrm{Sb}_{0.01}$. reported in various FH/HH composites containing large particles of the FH inclusions [11, 15]. It is interesting to note the large difference in the carrier density of samples with $\mathrm{x}=0.03$ and 0.04 at the temperature below $673 \mathrm{~K}$ despite the similarity in their thermopower values in the same temperature range. This abnormal trend suggests larger carrier effective mass

$\left(\mathrm{m}^{*}\right)$ for the sample with $\mathrm{x}=0.04$ compared to the sample with $\mathrm{x}=0.03$.

The mobility for all samples decreases with increasing temperature and increasing FH content (Figure 4D). At $300 \mathrm{~K}$, the mobility for the $2.5 \% \mathrm{Sb}$-doped matrix $(\mathrm{x}=0)$ is $43 \mathrm{~cm}^{2} / \mathrm{V} \cdot \mathrm{s}$, which is twice the mobility measured in undoped $\mathrm{HH}$ matrix with similar composition (Figure 5D). ${ }^{[10]}$ This simultaneous increase in both carrier density and mobility for the $\mathrm{Zr}_{0.25} \mathrm{Hf}_{0.75} \mathrm{NiSn}_{0.975} \mathrm{Sb}_{0.025}$ sample suggests that $\mathrm{Sb}$ substitution at $\mathrm{Sn}$ site contributes a large fraction of high mobility extrinsic carriers to the matrix, which increases the overall mobility of conducting electrons. Upon increasing the FH content, the carrier's mobility decreases to 40 $\mathrm{cm}^{2} / \mathrm{V} \cdot \mathrm{s}$ for the samples with $\mathrm{x}=0.03$ and to $35 \mathrm{~cm}^{2} / \mathrm{V} \cdot \mathrm{s}$, for the sample with $\mathrm{x}=0.04$. The observed reduction in the mobility is consistent with the increase carrier concentration with the 
volume fraction of FH inclusions (increasing Ni content). The above discussion suggests that under heavily doped conditions electronic conduction in $\mathrm{Zr}_{0.25} \mathrm{Hf}_{0.75} \mathrm{Ni}_{1+}{ }_{\mathrm{x}} \mathrm{Sn}_{0.975} \mathrm{Sb}_{0.025}$ is controlled by the large fraction of high-energy extrinsic carriers. Similar behavior was reported in $\mathrm{Ti}_{0.1} \mathrm{Zr}_{0.9} \mathrm{Ni}_{1+\mathrm{x}} \mathrm{Sn}_{0.975} \mathrm{Sb}_{0.025}$ nanocomposites. ${ }^{[6]}$ In the $\mathrm{Zr}_{0.25} \mathrm{Hf}_{0.75} \mathrm{Ni}_{1+\mathrm{x}} \mathrm{Sn}_{0.975} \mathrm{Sb}_{0.025}$ nanocomposites, extrinsic carriers are provided through $\mathrm{Sb}$ doping at $\mathrm{Sn}$ sites and additional doping from metallic FH inclusions. Donor states from such dopants presumably occupy highenergy levels (shallow states) within the band gap of the $\mathrm{HH}$ matrix facilitating their transmission, upon thermal excitation, across the potential barrier at the nanoscale interface between $\mathrm{HH}$ matrix and sub-ten nanometer scale $\mathrm{FH}$ inclusions. Therefore, no significant reduction in the overall carrier density results from the filtering of low-energy carriers anticipated at the $\mathrm{FH} / \mathrm{HH}$ interfaces. This result suggests that in order to combine the concepts of doping and energy filtering for the optimization of the figure of merit of thermoelectric materials, one must strike a good balance between the fraction of high mobility extrinsic carriers provided through doping and the fraction of low energy intrinsic carriers filtered at the matrix/inclusion interfaces.

To probe this approach, we have reduced the doping level to $1 \% \mathrm{Sb}$ substitution at $\mathrm{Sn}$ sites. Figure 6A shows the temperature dependence of the electrical conductivity for $\mathrm{Zr}_{0.25} \mathrm{Hf}_{0.75} \mathrm{Ni}_{1+\mathrm{x}} \mathrm{Sn}_{0.99} \mathrm{Sb}_{0.01} \mathrm{FH} / \mathrm{HH}$ composites. Regardless of the temperature or volume fraction of FH nanoinclusions (i.e. concentration of excess Ni), 1\% Sb-doped samples show lower electrical conductivity compared to $\mathrm{FH} / \mathrm{HH}$ composites with $2.5 \% \mathrm{Sb}$ at $\mathrm{Sn}$ sites. The electrical conductivity decreases with increasing temperature in the measured temperature range suggesting that the samples are still heavily doped semiconductors. Regardless of the temperature, the electrical conductivity for $\mathrm{Zr}_{0.25} \mathrm{Hf}_{0.75} \mathrm{Ni}_{1+{ }_{x}} \mathrm{Sn}_{0.99} \mathrm{Sb}_{0.01}$ samples decreases with addition of excess Ni. For instance, the electrical conductivity of 1\% Sb doped HH matrix $(\mathrm{x}=0)$ is $2000 \mathrm{~S} / \mathrm{cm}$ at $300 \mathrm{~K}$. Upon addition of $4 \%$ excess $\mathrm{Ni}(\mathrm{x}=0.04)$, the electrical conductivity at $300 \mathrm{~K}$ decreases to $\sim 1700 \mathrm{~S} / \mathrm{cm}$ and further decreases to $1550 \mathrm{~S} / \mathrm{cm}$ for the composition with $\mathrm{x}=$ 0.05 . The lowest electrical conductivity $(\sim 1400 \mathrm{~S} / \mathrm{cm}$ at $300 \mathrm{~K}$ and $700 \mathrm{~S} / \mathrm{cm}$ at $775 \mathrm{~K})$ was observed for the sample with $\mathrm{x}=0.03$. The reduction in the electrical conductivity of $\mathrm{Zr}_{0.25} \mathrm{Hf}_{0.75} \mathrm{Ni}_{1+\mathrm{x}} \mathrm{Sn}_{0.99} \mathrm{Sb}_{0.01}$ samples compared to $\mathrm{Zr}_{0.25} \mathrm{Hf}_{0.75} \mathrm{Ni}_{1+\mathrm{x}} \mathrm{Sn}_{0.975} \mathrm{Sb}_{0.025}$ samples can be associated to: (1) a drop in the density of extrinsic carriers due to the reduction of the concentration of $\mathrm{Sb}$ dopant from $2.5 \%$ to $1 \%$; and (2) additional reductions in the carrier density, 
for compositions with varying $\mathrm{x}$ values, due to filtering of low-energy carriers at the $\mathrm{FH} / \mathrm{HH}$ interfaces. This analysis is supported by the carrier concentration measurement for various

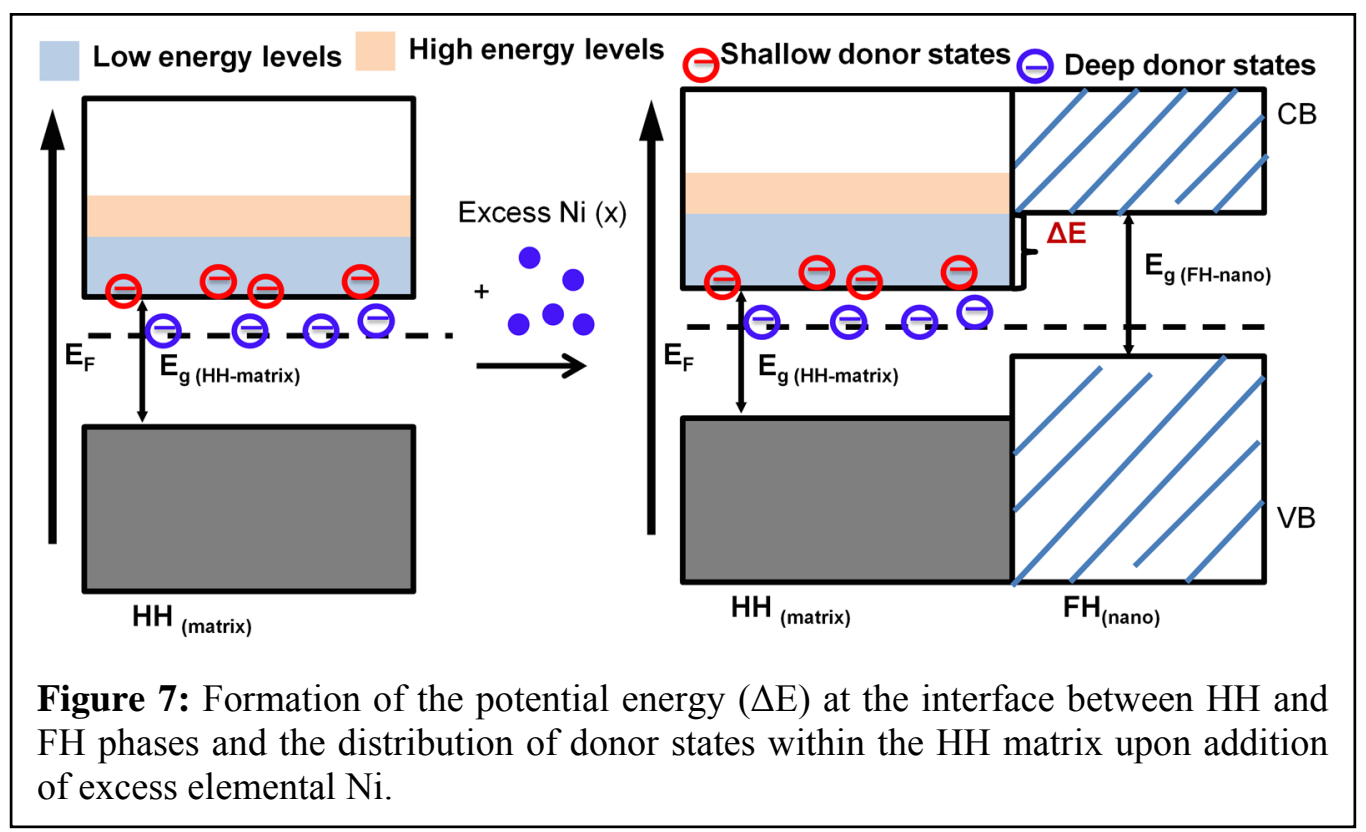

$\mathrm{Zr}_{0.25} \mathrm{Hf}_{0.75} \mathrm{Ni}_{1}$

${ }_{+} \mathrm{Sn}_{0.99} \mathrm{Sb}_{0.01}$

samples

(Figure 6C).

At $300 \mathrm{~K}$, the carrier

concentration

for the $1 \%$

Sb-doped HH

matrix is $35 \times$

$10^{19} \mathrm{~cm}^{-3}$.

This is $30 \%$

lower than the value measured for the $2.5 \% \mathrm{Sb}$-doped $\mathrm{HH}$ matrix and is consistent with the addition of $20 \times 10^{19}$ carriers per $\mathrm{cm}^{3}$ anticipated from the substitution of $0.01 \mathrm{Sn}$ by $\mathrm{Sb}$ in $\mathrm{Zr}_{0.25} \mathrm{Hf}_{0.75} \mathrm{NiSn}$. Upon addition of $3 \%$ excess $\mathrm{Ni}(97 \% \mathrm{HH} / 3 \% \mathrm{FH})$ in the $1 \% \mathrm{Sb}$-doped $\mathrm{HH}$ matrix, the carrier density at $300 \mathrm{~K}$ decreases to $\sim 23 \times 10^{19} \mathrm{~cm}^{-3}$, which is $34 \%$ lower compared to $1 \% \mathrm{Sb}$-doped $\mathrm{HH}$ matrix $(\mathrm{x}=0)$. Increasing the volume fraction of $\mathrm{FH}$ inclusion to $4 \%$ and $5 \%$ resulted in a marginal increase of the carrier density at $300 \mathrm{~K}$ to $\sim 26 \times 10^{19} \mathrm{~cm}^{-3}$ and $30 \times 10^{19} \mathrm{~cm}^{-}$ ${ }^{3}$, respectively. The observed small increase in the carrier density for samples with $\mathrm{x}=0.04$ and 0.05 compared to the sample with $\mathrm{x}=0.03$, suggests that increasing the concentration of excess $\mathrm{Ni}$ resulted in the formation of a small fraction of large $\mathrm{FH}$ inclusions, which contribute additional carriers in the matrix. However, the overall carrier density within samples containing FH nanoinclusions generally remains lower than that of the $1 \% \mathrm{Sb}$-doped $\mathrm{HH}$ matrix.

Careful analysis of the temperature dependent carrier density curves for $\mathrm{Zr}_{0.25} \mathrm{Hf}_{0.75} \mathrm{Ni}_{1+\mathrm{x}} \mathrm{Sn}_{0.99} \mathrm{Sb}_{0.01}$ samples reveals that the carrier density initially remains unchanged upon increasing temperature up to a critical value, $\mathrm{T}_{\mathrm{c}}$, beyond which a nearly exponential increase in the carrier density with temperature is observed. For the 1\% Sb-doped $\mathrm{HH}$ matrix, thermal excitation of carriers from the valence band (VB) to the conduction band (CB) is observed at temperatures above $T_{c}=675 \mathrm{~K}$. Interestingly, the critical temperature, $T_{c}$, for 
samples containing FH nanoinclusions decreases with increasing volume fraction of FH content (increasing Ni content), while the carrier density below $\mathrm{T}_{\mathrm{c}}$ increases. For instance, the carrier density for the sample with $\mathrm{x}=0.03$ remains constant at $23 \times 10^{19} \mathrm{~cm}^{-3}$ up to $\mathrm{T}_{\mathrm{c}}=675 \mathrm{~K}$. Upon increasing the $\mathrm{FH}$ content to $\mathrm{x}=0.04$, the carrier density increases to $26 \times 10^{19} \mathrm{~cm}^{-3}$ and remains constant up to $\mathrm{T}_{\mathrm{c}}=625 \mathrm{~K}$. Further increasing the $\mathrm{FH}$ content to $\mathrm{x}=0.05$ results in carrier density of $30 \times 10^{19} \mathrm{~cm}^{-3}$, which remains constant up to $\mathrm{T}_{\mathrm{c}}=575 \mathrm{~K}$. The observed change in the carrier concentration of $\mathrm{Zr}_{0.25} \mathrm{Hf}_{0.75} \mathrm{Ni}_{1+{ }_{x}} \mathrm{Sn}_{0.99} \mathrm{Sb}_{0.01}$ samples with increasing $\mathrm{Ni}$ content (increasing volume fraction of FH inclusion) and the temperature dependence of the carrier density above $\mathrm{T}_{\mathrm{c}}$ can be explained by taking into account the relative alignment of conduction bands (CBs) at the FH/HH interfaces (Figure 7).

For instance, the addition of excess $\mathrm{Ni}$ into a $\mathrm{HH}$ matrix results in the formation of coherent FH phase with varying particle size. The energy difference of conduction band minima $(\mathrm{CBM})$ between the $\mathrm{HH}$ matrix and the $\mathrm{FH}$ inclusions generates an energy barrier, $\Delta \mathrm{E}$, at the $\mathrm{FH} / \mathrm{HH}$ interface, the heights of which decreases with increasing size of the FH inclusion. Such potential energy barrier acts as a filter of low-energy extrinsic carriers (Figure 7) while enabling transmission of high-energy extrinsic carriers. Therefore, the temperature dependence of the carrier density for samples with $\mathrm{x}=0.03,0.04$ and 0.05 at temperatures above $\mathrm{T}_{\mathrm{c}}$ arises from the thermal excitation of existing extrinsic carriers from donor states at low energy across the potential barrier, $\Delta \mathrm{E}$, at the $\mathrm{FH} / \mathrm{HH}$ interfaces, rather than from excitation of intrinsic carrier from the valence band (VB) to the conduction band (CB) as observed in the case of $1 \% \mathrm{Sb}$ doped HH matrix at temperatures above $675 \mathrm{~K}$. This analysis suggests that starting with a matrix with the carrier density of $35 \times 10^{19} \mathrm{~cm}^{-3}$, the addition of increasing excess $\mathrm{Ni}$ results in the formation of $\mathrm{FH}$ nanostructures with increasing average particle size leading to the formation of potential energy barrier, $\Delta \mathrm{E}$, with decreasing height (Figure 7) at the heterojunction between $\mathrm{HH}$ matrix and FH nanoinclusions.

The reduction in the carrier density of $\mathrm{Zr}_{0.25} \mathrm{Hf}_{0.75} \mathrm{Ni}_{1+\times} \mathrm{Sn}_{0.99} \mathrm{Sb}_{0.01}$ samples with increasing $\mathrm{Ni}$ content resulted in an increase in the absolute value of the thermopower (Figure 6B). All samples exhibit negative values of the thermopower indicating $n$-type semiconducting behavior. Regardless of the temperature, samples of $\mathrm{Zr}_{0.25} \mathrm{Hf}_{0.75} \mathrm{Ni}_{1+\mathrm{x}} \mathrm{Sn}_{0.99} \mathrm{Sb}_{0.01}$ show larger thermopower values compared to corresponding samples (constant $x$ ) in $\mathrm{Zr}_{0.25} \mathrm{Hf}_{0.75} \mathrm{Ni}_{1+\mathrm{x}} \mathrm{Sn}_{0.975} \mathrm{Sb}_{0.025}$ nanocomposites. This result is consistent with the reduction of the Sb doping level and carrier 

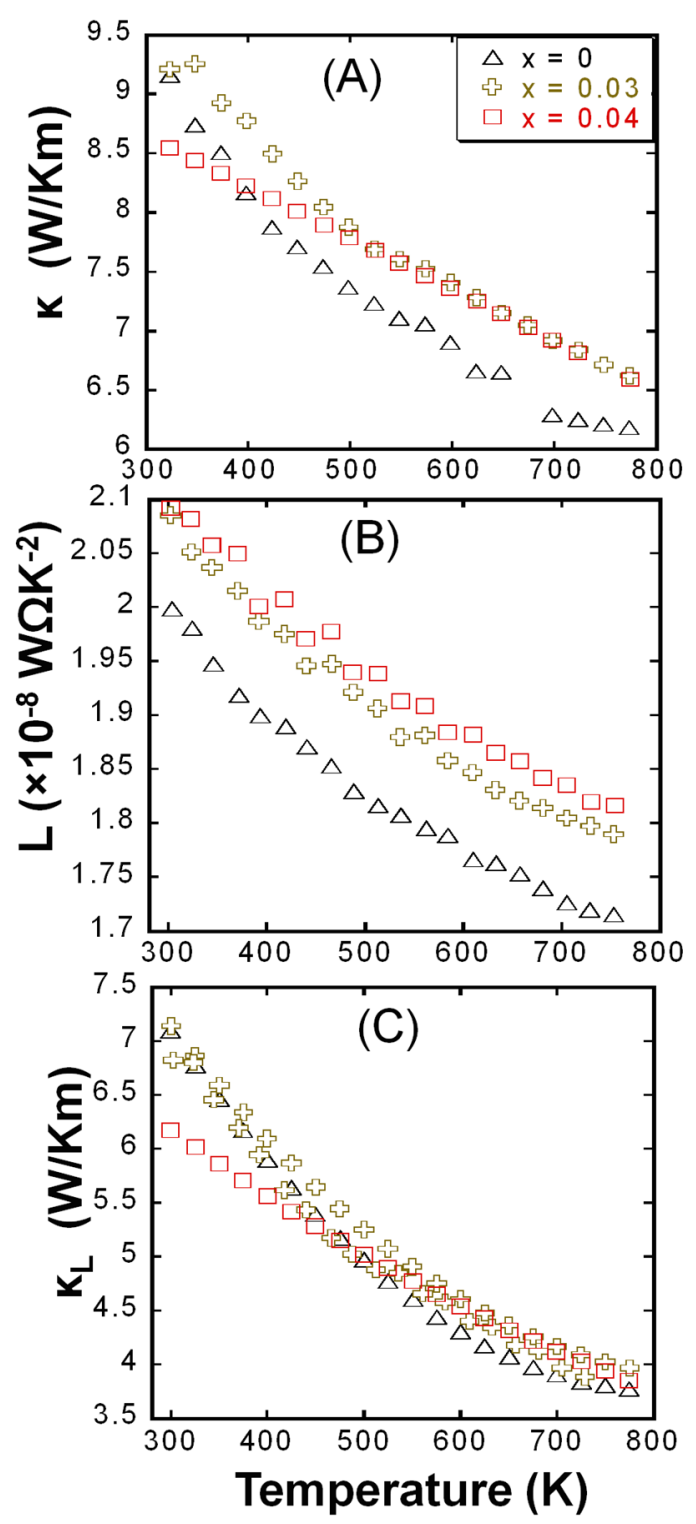

Figure 8: Temperature dependence of (A) total thermal conductivity; (B) Lorenz number and (C) lattice thermal conductivity for $\mathrm{Zr}_{0.25} \mathrm{Hf}_{0.75} \mathrm{Ni}_{1+\mathrm{x}} \mathrm{Sn}_{0.975} \mathrm{Sb}_{0.025}$.

density. The thermopower of $\mathrm{Zr}_{0.25} \mathrm{Hf}_{0.75} \mathrm{Ni}_{1+\mathrm{x}} \mathrm{Sn} 0 .{ }_{99} \mathrm{Sb}_{0.01}$ samples increases with rising temperature. At $300 \mathrm{~K}$, the thermopower of $1 \% \mathrm{Sb}$-doped matrix is -93 $\mu \mathrm{V} / \mathrm{K}$ and rapidly increases to $-163 \mu \mathrm{V} / \mathrm{K}$ at $775 \mathrm{~K}$. Upon addition of excess $\mathrm{Ni}$, the thermopower value for samples with $\mathrm{x}=0.03$, 0.04 and 0.05 slightly increases to $\sim-100$ $\mu \mathrm{V} / \mathrm{K}$ at $300 \mathrm{~K}$ and $-180 \mu \mathrm{V} / \mathrm{K}$ at $775 \mathrm{~K}$.

Figure 6D shows the temperature dependence of the mobility of $1 \% \mathrm{Sb}$-doped $\mathrm{FH} / \mathrm{HH}$ samples. The mobility for all samples linearly decreases with increasing temperature. The matrix and samples with $\mathrm{x}$ $=0.03$ shows similar value $\left(35 \mathrm{~cm}^{2} / \mathrm{V} \cdot \mathrm{s}\right.$ at $300 \mathrm{~K}$ ) of the mobility in the measured temperature range. However, the sample with $\mathrm{x}=0.04$ displays a slightly higher carrier mobility compared to the $1 \% \mathrm{Sb}$-doped matrix, which is consistent with the observed decrease in the effective carrier density. The sample with $\mathrm{x}=0.05$ has the lowest mobility value $\left(30 \mathrm{~cm}^{2} / \mathrm{V} \cdot \mathrm{s}\right.$ at $\left.300 \mathrm{~K}\right)$ in the measured temperature range. This is consistent with the observed large carrier density. The fitting of the temperature dependence of the carrier mobility of $\mathrm{Zr}_{0.25} \mathrm{Hf}_{0.75} \mathrm{Ni}_{1+x} \mathrm{Sn}_{0.99} \mathrm{Sb}_{0.01}$ using the power law $\mathrm{T}^{-\lambda}$ results in $\lambda$ values of 1.38 for the matrix, 1.30 for the sample with $\mathrm{x}=0.03$ and 1.60 for the sample with $\mathrm{x}=0.05$ indicating that acoustic phonon scattering dominates carrier transport in these samples. 
Figure 8 shows the temperature dependence of the total thermal conductivity, the Lorenz number and the lattice thermal conductivity for $\mathrm{Zr}_{0.25} \mathrm{Hf}_{0.75} \mathrm{Ni}_{1+\mathrm{x}} \mathrm{Sn}_{0.975} \mathrm{Sb}_{0.025} \mathrm{FH} / \mathrm{HH}$ composites. The total thermal conductivity for all samples decreases with increasing temperature (Figure 8A). At $300 \mathrm{~K}$, the sample with $\mathrm{x}=0.04$ has the lowest total thermal conductivity $(\sim 8.5 \mathrm{~W} / \mathrm{Km})$. Upon increasing the temperature above $500 \mathrm{~K}$, similar values of the thermal conductivity are observed for samples with $\mathrm{x}$ $=0.03$ and 0.04 . At $775 \mathrm{~K}$, a total thermal conductivity of $6.5 \mathrm{~W} / \mathrm{Km}$ was observed for both compositions ( $\mathrm{x}$ $=0.03$ and 0.04); whereas the 2.5\% Sb-doped $\mathrm{HH}$ matrix shows the lowest thermal conductivity (6.2 $\mathrm{W} / \mathrm{Km}$ ). In order to determine the electronic contribution to the thermal conductivity $\left(\kappa_{\mathrm{e}}=\mathrm{L} \sigma \mathrm{T}\right.$, where $\mathrm{L}$ is the Lorenz number, $\mathrm{T}$ is the absolute temperature), the Lorenz number was calculated from the experimental thermopower using a single parabolic band (SPB) model ${ }^{[49,50]}$ (Figure 8B). The Lorenz number for all samples is lower than that of the free electron model $2.45 \times 10^{-8}{\mathrm{~W} \Omega \mathrm{K}^{-2}}^{2}$ Regardless of the temperature, the Lorenz number increases with increasing Ni concentration. At $300 \mathrm{~K}$,

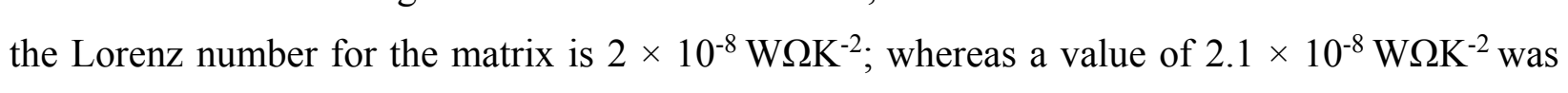
observed for the samples with $\mathrm{x}=0.03$ and 0.04 . The lattice thermal conductivity (Figure $8 \mathrm{C}$ ) was obtained by subtracting the electronic thermal conductivity from the total thermal conductivity. The $2.5 \% \mathrm{Sb}$-doped $\mathrm{HH}$ matrix $(\mathrm{x}=0)$ and the sample with $\mathrm{x}=0.03$ show similar values of the lattice thermal conductivity at $300 \mathrm{~K}(\sim 7 \mathrm{~W} / \mathrm{Km})$; whereas the sample with $\mathrm{x}=0.04$ has the lowest lattice thermal conductivity at $300 \mathrm{~K}(\sim 6.2 \mathrm{~W} / \mathrm{Km})$. The reduction in the lattice thermal conductivity for the samples with $\mathrm{x}=0.04$ is probably due to additional phonon 
scattering at the high-density $\mathrm{FH} / \mathrm{HH}$ interfaces that form with the increasing $\mathrm{Ni}$ content. Increasing the temperature results in a rapid drop of the lattice thermal conductivity of all samples to $\sim 3.9 \mathrm{~W} / \mathrm{K}-\mathrm{m}$ at $775 \mathrm{~K}$.

Figure 9 shows the temperature dependence of the total thermal conductivity, the Lorenz number and the lattice thermal conductivity for $\mathrm{Zr}_{0.25} \mathrm{Hf}_{0.75} \mathrm{Ni}_{1+{ }_{x}} \mathrm{Sn}_{0.99} \mathrm{Sb}_{0.01} \mathrm{FH} / \mathrm{HH}$ composites. The reduction in the $\mathrm{Sb}$ doping to $1 \%$ results in a lower total thermal conductivity for all $\mathrm{Zr}_{0.25} \mathrm{Hf}_{0.75} \mathrm{Ni}_{1+\mathrm{x}} \mathrm{Sn}_{0.99} \mathrm{Sb}_{0.01}$ samples when compared to the $\mathrm{Zr}_{0.25} \mathrm{Hf}_{0.75} \mathrm{Ni}_{1+\mathrm{x}} \mathrm{Sn}_{0.975} \mathrm{Sb}_{0.025}$ composites. This is due to the decrease in the density of donor states (from Sb dopant), which
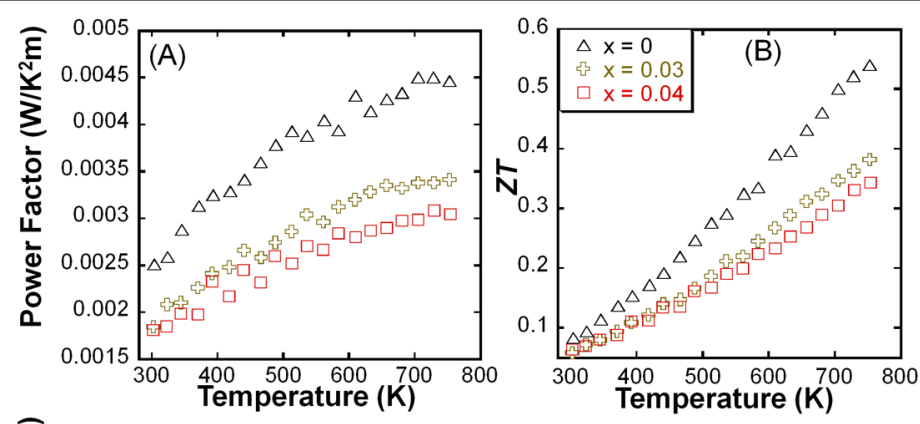

will affect the electronic thermal conductivity.

Regardless of temperature, the total thermal conductivity of $\mathrm{Zr}_{0.25} \mathrm{Hf}_{0.75} \mathrm{Ni}_{1+\times} \mathrm{Sn}_{0.99} \mathrm{Sb}_{0.01}$

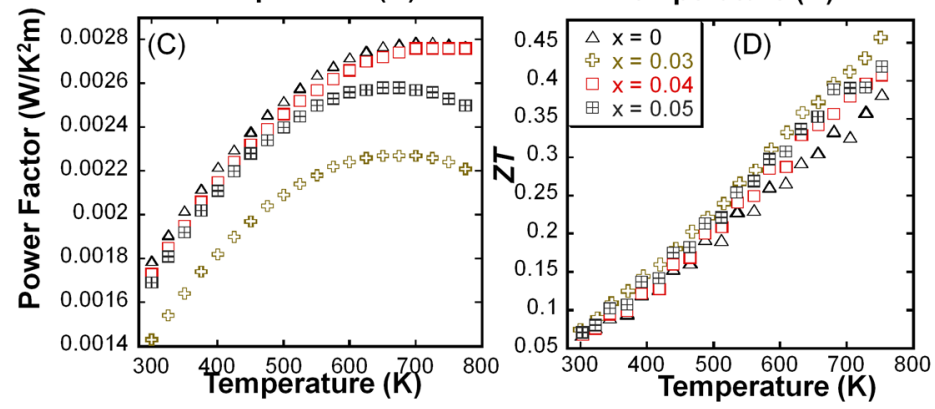
composites first decreases to the lowest value as the volume fraction of $\mathrm{FH}$ inclusion increases to $3 \%$, then the thermal conductivity increases

Figure 10: Temperature dependence of (A) Power factor, (B) $\mathrm{ZT}$ for the composites $\mathrm{Zr}_{0.25} \mathrm{Hf}_{0.75} \mathrm{Ni}_{1+\mathrm{x}} \mathrm{Sn}_{0.975} \mathrm{Sb}_{0.025}$; and (C) Power factor, (D) $\mathrm{ZT}$ for the composites $\mathrm{Zr}_{0.25} \mathrm{Hf}_{0.75} \mathrm{Ni}_{1+\times} \mathrm{Sn}_{0.99} \mathrm{Sb}_{0.01}$. with further increase of FH content to $4 \%$ and $5 \%$. The largest total thermal conductivity was observed for the 1\% Sb-doped HH matrix. As before, the Lorenz number was calculated assuming a SPB model (Figure 9B) to extract the contribution from the electronic thermal conductivity. The Lorenz number for all $1 \%$ Sb-doped samples is lower than the values observed for $\mathrm{Zr}_{0.25} \mathrm{Hf}_{0.75} \mathrm{Ni}_{1+\mathrm{x}} \mathrm{Sn}_{0.975} \mathrm{Sb}_{0.025}$ composites. The matrix has the highest Lorenz number $\left(1.95 \times 10^{-8}\right.$ $\mathrm{W} \Omega \mathrm{K}^{-2}$ at $300 \mathrm{~K}$ ) in the measured temperature range. Upon increasing the $\mathrm{FH}$ content to $\mathrm{x}=0.03$, 0.04 and 0.05 , the Lorenz number decreases to $1.9 \times 10^{-8}{\mathrm{~W} \Omega \mathrm{K}^{-2}}^{2}$ at $300 \mathrm{~K}$. 
Regardless of the temperature, the lattice thermal conductivity (Figure 9C) decreases with increasing volume fraction of the FH phase (excess Ni concentration). At $300 \mathrm{~K}$, the sample with $\mathrm{x}=0.03$ shows the lowest value $(\sim 4.8 \mathrm{~W} / \mathrm{Km}$ at $300 \mathrm{~K})$ of the lattice thermal conductivity. Although the lattice thermal conductivity for the samples with $\mathrm{x}=0.04$ and 0.05 slightly increases with increasing FH content, the values are lower than that of the matrix $(7 \mathrm{~W} / \mathrm{Km}$ at $300 \mathrm{~K})$. The reduction in the lattice thermal conductivity is attributed to phonon scattering from at the $\mathrm{FH} / \mathrm{HH}$ interfaces.

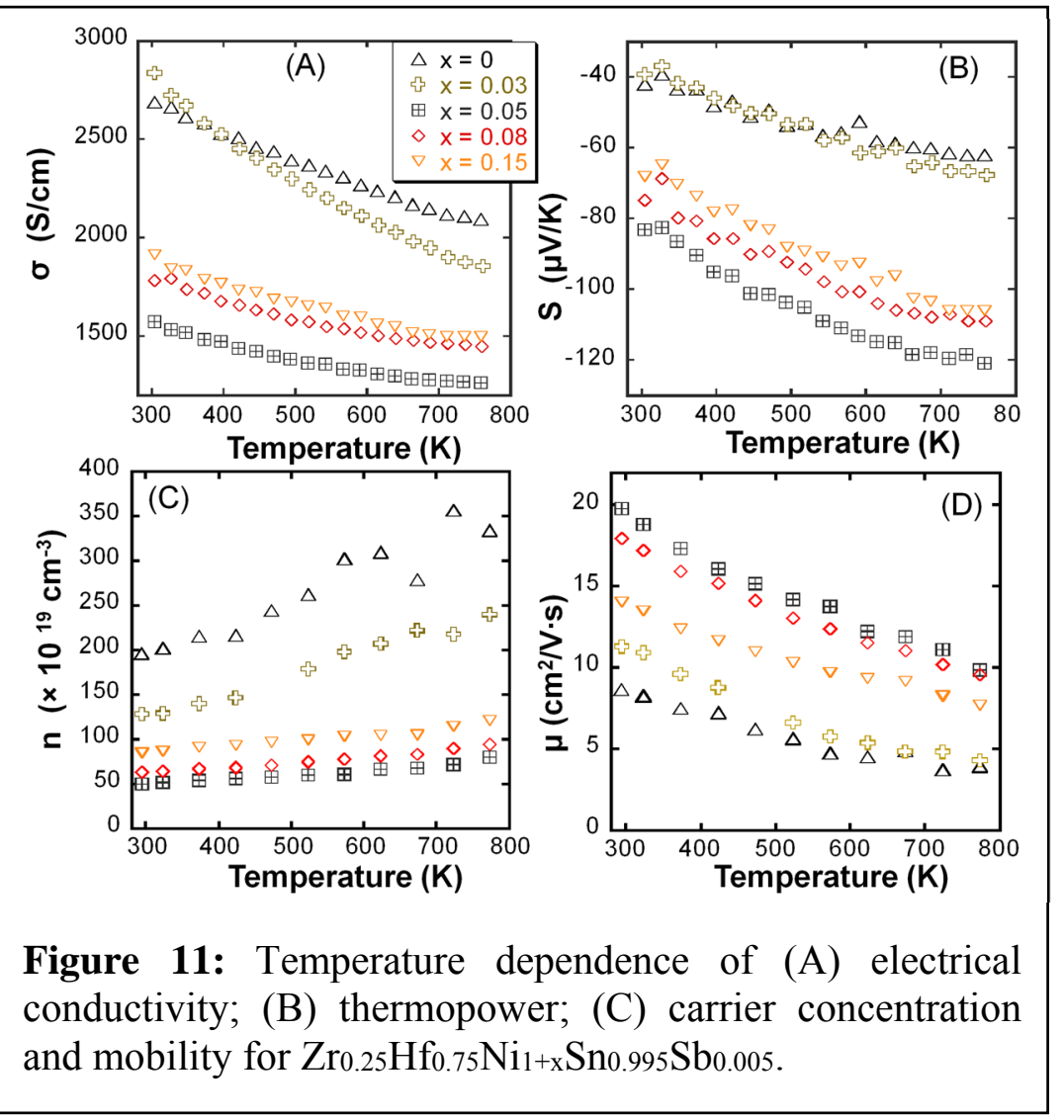
The measured electrical
conductivity and thermopower
are used to evaluate the power
factor for the
$\mathrm{Zr}_{0.25} \mathrm{Hf}_{0.75} \mathrm{Ni}_{1+\mathrm{x}} \mathrm{Sn}_{0.975} \mathrm{Sb}_{0.025}$
(Figure $\quad 10 \mathrm{~A}$ ) and $\mathrm{Zr} 0.25 \mathrm{Hf}_{0.75} \mathrm{Ni}_{1+\times} \mathrm{Sn}_{0.99} \mathrm{Sb}_{0.01}$ (Figure 10C) composites. The highest electrical conductivity and the thermopower are observed for the $2.5 \% \mathrm{Sb}-$ doped HH matrix, resulting in the largest power factor in the measured temperature range. The combination of large power factor and low thermal conductivity for the $2.5 \% \mathrm{Sb}$-doped matrix leads to the largest $\mathrm{ZT}$ value of 0.55 at $775 \mathrm{~K}$ (Figure 10B). Upon increasing the volume fraction of $\mathrm{FH}$ inclusion to $3 \%$ and $4 \%$, the power factor and ZT value decrease. The ZT value for the samples with $\mathrm{x}=0.03$ and 0.04 are respectively, 0.4 and 0.35 at $775 \mathrm{~K}$. Samples of the $\mathrm{Zr}_{0.25} \mathrm{Hf}_{0.75} \mathrm{Ni}_{1+\mathrm{x}} \mathrm{Sn}_{0.99} \mathrm{Sb}_{0.01}$ composites show lower power factor than that of composites with $2.5 \% \mathrm{Sb}$ substitution. This is due to the reduction in the electrical conductivity. At $300 \mathrm{~K}$, the matrix and the samples with $\mathrm{x}=0.04$ and 0.05 show a similar power factor $\left(18 \times 10^{-4} \mathrm{WK}^{-2} \mathrm{~m}^{-1}\right)$, while the sample with $\mathrm{x}=0.03$ exhibits the lowest power factor value $\left(14 \times 10^{-4} \mathrm{WK}^{-2} \mathrm{~m}^{-1}\right.$ (Figure 10C). However, the ZT values for all $1 \% \mathrm{Sb}$-doped samples do not 
change significantly at low temperatures, despite large differences in the power factor. The highest ZT value for $1 \%$ Sb-doped samples is 0.46 observed at $775 \mathrm{~K}$ for the sample with $\mathrm{x}=$
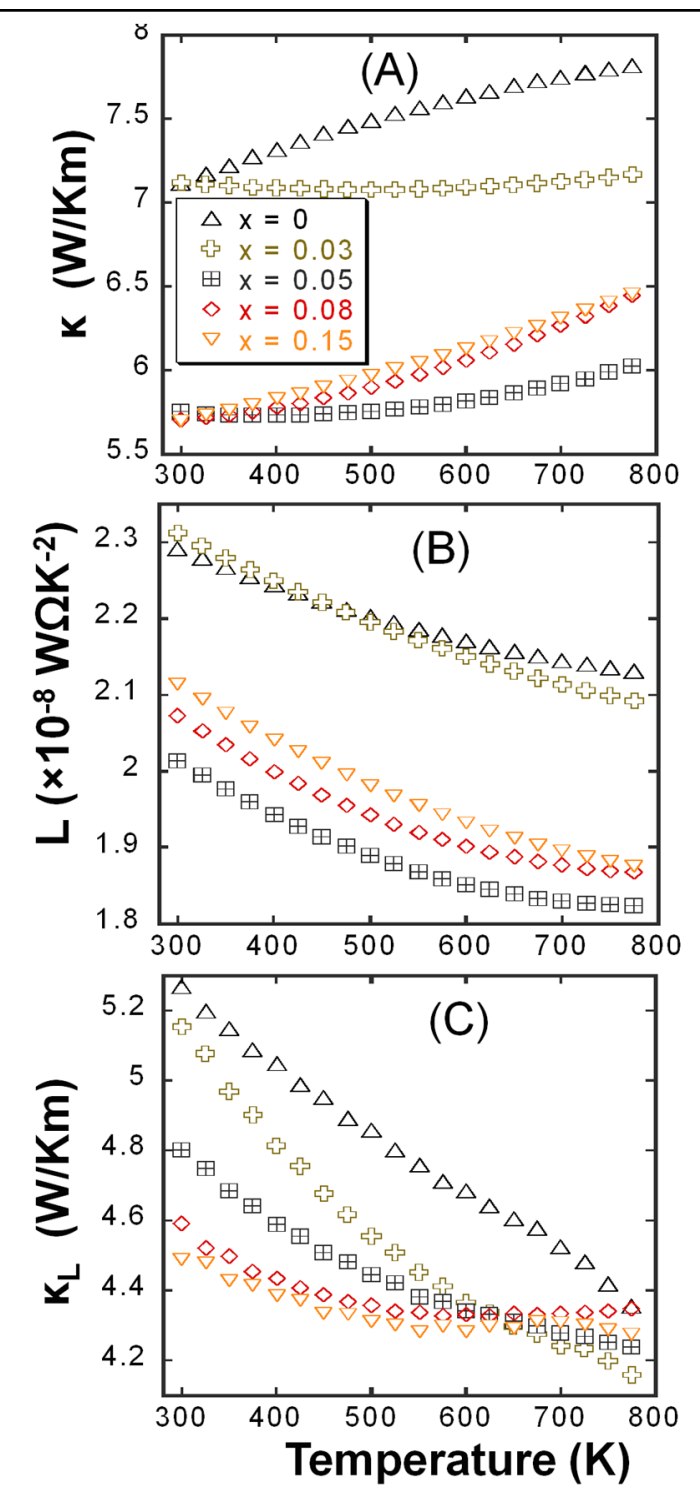

Figure 12: Temperature dependence of

(A) total thermal conductivity;

Lorenz number and $(\mathrm{C})$ lattice thermal conductivity

for

$\mathrm{Zr}_{0.25} \mathrm{Hf}_{0.75} \mathrm{Ni}_{1+\mathrm{x}} \mathrm{Sn}_{0.995} \mathrm{Sb}_{0.005}$
0.03 (Figure 10D).

It appears from the above discussion that for $\mathrm{Zr}_{0.25} \mathrm{Hf}_{0.75} \mathrm{Ni}_{1+\mathrm{x}} \mathrm{Sn}_{1-\mathrm{y}} \mathrm{Sb}_{\mathrm{y}}$ samples with $\mathrm{y}=0.01$ and 0.025 , donor states arising from doping through $\mathrm{Sb}$ substitutions at $\mathrm{Sn}$ sites and/or from doping by large metallic FH inclusions dominate the electronic conduction. The formation of $\mathrm{HH} / \mathrm{FH}$ interfaces through addition of excess elemental $\mathrm{Ni}(\mathrm{x})$ resulted in a marginal change in the carrier density compared to the pristine $\mathrm{HH}$ matrix. This result is in sharp contradiction with the large reduction in the overall carrier density observed in for $\mathrm{Zr}_{0.25} \mathrm{Hf}_{0.75} \mathrm{Ni}_{1+}{ }_{+} \mathrm{Sn} 0.975 \mathrm{Bi} 0.025$ composites ${ }^{[10]}$ and suggests that a large fraction of donor states, from $\mathrm{Sb}$ dopants and $\mathrm{FH}$ inclusions in $\mathrm{Zr}_{0.25} \mathrm{Hf}_{0.75} \mathrm{Ni}_{1+\mathrm{x}} \mathrm{Sn}_{1-\mathrm{y}} \mathrm{Sb}_{\mathrm{y}}$ samples, occupy high energy levels (shallow states) within the band gap of the $\mathrm{HH}$ matrix enabling their easy thermal excitation above the potential energy barrier at the $\mathrm{HH} / \mathrm{FH}$ interfaces. Carriers from such shallow states are therefore transparent to the $\mathrm{FH}$ inclusions present within the $\mathrm{HH}$ matrix.

To probe this hypothesis, we have investigated electronic transport in $\mathrm{Zr}_{0.25} \mathrm{Hf}_{0.75} \mathrm{Ni}_{1+\mathrm{x}} \mathrm{Sn}_{0.995} \mathrm{Sb}_{0.005} \quad$ nanocomposites unintentionally doped with a large fraction of lowenergy carriers along with a trace amount of $\mathrm{Sb}$ dopant. These samples were obtained by mechanically alloying $\mathrm{Zr}_{0.25} \mathrm{Hf}_{0.75} \mathrm{Ni}_{1+x} \mathrm{Sn}_{0.995} \mathrm{Sb}_{0.005}$ 
samples, pre-synthesized by solid-state reaction, using a high-energy shaker ball mill system and stainless steel balls and jar. This processing condition enables accidental doping of $\mathrm{Zr}_{0.25} \mathrm{Hf}_{0.75} \mathrm{Ni}_{1+\times} \mathrm{Sn}_{0.995} \mathrm{Sb}_{0.005}$ samples by impurities such as $\mathrm{Fe}$ from the stainless steel jars and balls during the high-energy shaker milling process.

Figure 11A shows the temperature dependence of electrical conductivity for $\mathrm{Zr}_{0.25} \mathrm{Hf}_{0.75} \mathrm{Ni}_{1+\times} \mathrm{Sn}_{0.995} \mathrm{Sb}_{0.005}$ samples. Regardless of the temperature, the electrical conductivity is lower than that of $\mathrm{Zr}_{0.25} \mathrm{Hf}_{0.75} \mathrm{Ni}_{1+\mathrm{x}} \mathrm{Sn}_{0.975} \mathrm{Sb}_{0.025}$. The electrical conductivity for all samples decreases with increasing temperature suggesting heavily doped semiconducting behavior. The electrical conductivity of $\mathrm{Zr}_{0.25} \mathrm{Hf}_{0.75} \mathrm{Ni}_{1+\times} \mathrm{Sn}_{0.995} \mathrm{Sb}_{0.005}$ samples in the measured temperature range decreases upon addition of $\mathrm{FH}$ nanoinclusions. The matrix has the highest value of the electrical conductivity $(2700 \mathrm{~S} / \mathrm{cm}$ at $300 \mathrm{~K})$. When the volume fraction of $\mathrm{FH}$ phases $(\mathrm{Ni}$ concentration) increases to $5 \%$, the electrical conductivity reaches the lowest value $(1500 \mathrm{~S} / \mathrm{cm}$ at $300 \mathrm{~K}$ ); and remains nearly unchanged with further increasing $\mathrm{FH}$ volume fraction to $8 \%$ and $15 \%$. It should be noted that the electrical conductivity for the samples with FH nanoinclusions is lower or equal to that of the matrix within the measured temperature range.
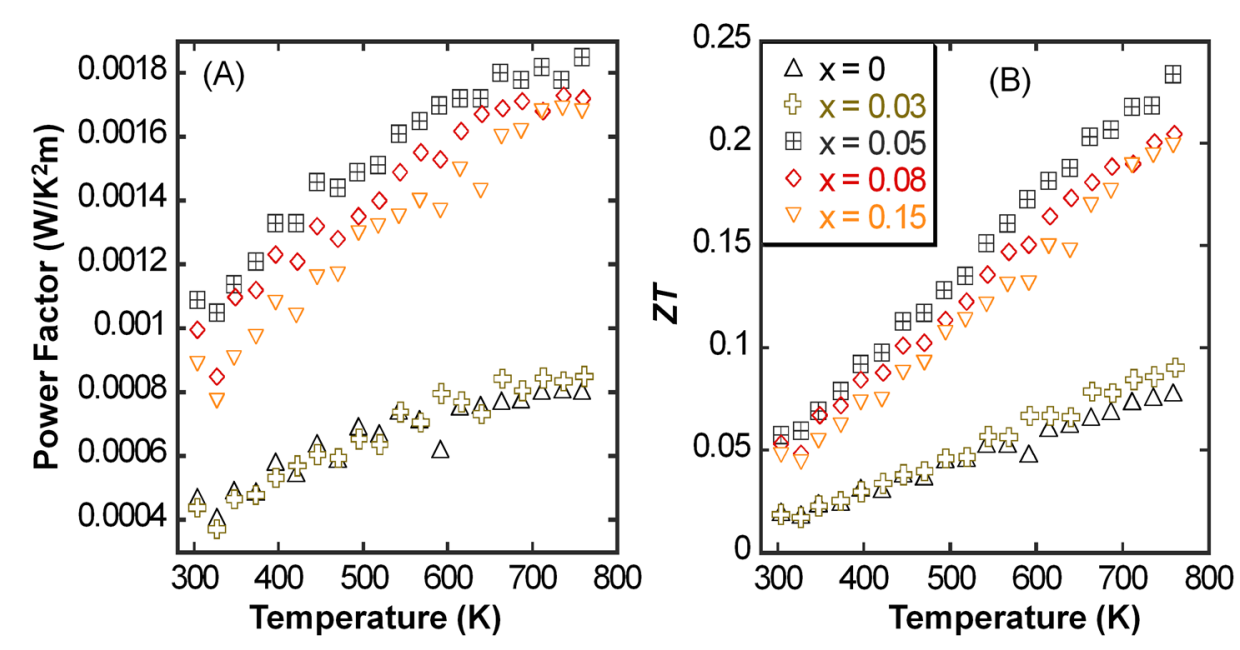

Figure 13: Temperature dependence of (A) power factor and (B) ZT for $\mathrm{Zr}_{0.25} \mathrm{Hf}_{0.75} \mathrm{Ni}_{1+\times} \mathrm{Sn}_{0.995} \mathrm{Sb}_{0.005}$.

The thermopower for all $\mathrm{Zr}_{0.25} \mathrm{Hf}_{0.75} \mathrm{Ni}_{1+\mathrm{x}} \mathrm{Sn}_{0.995} \mathrm{Sb}_{0.005}$ samples increases almost linearly with increasing temperature and maintains negative values indicating $n$-type semiconducting behavior (Figure 11B). Regardless of temperature, the thermopower remains constant or increases upon addition of FH phase. The matrix and the sample with $\mathrm{x}=0.03$ have similar 
thermopower $(-40 \mu \mathrm{V} / \mathrm{K}$ at $300 \mathrm{~K}$ and $-65 \mu \mathrm{V} / \mathrm{K}$ at $775 \mathrm{~K})$. As the $\mathrm{FH}$ content increases to $5 \%$, the thermopower increases to $-80 \mu \mathrm{V} / \mathrm{K}$ at $300 \mathrm{~K}$, which corresponds to $200 \%$ enhancement compared to the $0.5 \% \mathrm{Sb}$-doped matrix. Further increasing the $\mathrm{FH}$ content to $8 \%$ and $15 \%$ resulted in a slight drop in the thermopower to $-75 \mu \mathrm{V} / \mathrm{K}$ and $-70 \mu \mathrm{V} / \mathrm{K}$ at $300 \mathrm{~K}$, respectively. However, the observed values remain larger than that of the $0.5 \% \mathrm{Sb}$-doped matrix.

Figure 11C shows the temperature dependence of the carrier concentration for $\mathrm{Zr}_{0.25} \mathrm{Hf}_{0.75} \mathrm{Ni}_{1+\mathrm{x}} \mathrm{Sn}_{0.995} \mathrm{Sb}_{0.005}$. It is interesting to note that despite the low Sb-doping level, the carrier concentration in all $\mathrm{Zr}_{0.25} \mathrm{Hf}_{0.75} \mathrm{Ni}_{1+\mathrm{x}} \mathrm{Sn}_{0.995} \mathrm{Sb}_{0.005}$ samples is one-order of magnitude higher than that of $\mathrm{Zr}_{0.25} \mathrm{Hf}_{0.75} \mathrm{Ni}_{1+} \mathrm{Sn}_{0.975} \mathrm{Sb}_{0.025}$ and $\mathrm{Zr}_{0.25} \mathrm{Hf}_{0.75} \mathrm{Ni}_{1+\times} \mathrm{Sn}_{0.99} \mathrm{Sb}_{0.01}$ samples. The measured carrier density of $200 \times 10^{19} \mathrm{~cm}^{-3}$ at $300 \mathrm{~K}$ is 20 times larger than the increase in the carrier density expected from the substitution of $0.5 \% \mathrm{Sn}$ by $\mathrm{Sb}$ in $\mathrm{Zr}_{0.25} \mathrm{Hf}_{0.75} \mathrm{NiSn}$ matrix. This discrepancy can be explained by the presence of a trace amount of metallic Fe impurities in the $0.5 \% \mathrm{Sb}$-doped $\mathrm{HH}$ samples processed by mechanical alloying process. These Fe impurities act as donor states providing, upon thermal excitation, additional carriers to the matrix. This results in the observed larger overall effective carrier concentration. Regardless of the temperature, the carrier density drastically decreases with the addition of FH inclusions. This suggests that a large fraction of donor states from Fe impurities are affected by the energy filtering effect at the $\mathrm{HH} / \mathrm{FH}$ interfaces, unlike donor states originating from Sb-doping, which are generally not affected. The $0.5 \% \mathrm{Sb}$-doped matrix displays the highest carrier concentration in the measured temperature range $\left(200 \times 10^{19} \mathrm{~cm}^{-3}\right.$ at $300 \mathrm{~K}$ and $360 \times 10^{19} \mathrm{~cm}^{-3}$ at $\left.775 \mathrm{~K}\right)$. As the volume fraction of $\mathrm{FH}$ inclusion increases to $3 \%$, the carrier density drops to $125 \times 10^{19} \mathrm{~cm}^{-3}$ at $300 \mathrm{~K}$. The carrier density further decreases to the lowest value, $50 \times 10^{19} \mathrm{~cm}^{-3}$ at $300 \mathrm{~K}$ as the FH content increases to $5 \%$, which corresponds to $75 \%$ drop compared to the $0.5 \%$ Sb-doped matrix. However, when the $\mathrm{FH}$ content increases to $8 \%$ and $15 \%$, the carrier concentration of the resulting composites slightly increases to $60 \times 10^{19} \mathrm{~cm}^{-3}$ and $90 \times 10^{19} \mathrm{~cm}^{-3}$ at $300 \mathrm{~K}$, respectively. Interestingly, these values of the carrier density remain lower than that of the $0.5 \% \mathrm{Sb}$-doped matrix. The marginal increase in the carrier density can be ascribed to additional doping arising from the formation of large FH metallic nanoinclusions in the matrix. These donor states from FH inclusions are presumably not affected by the potential barrier at the $\mathrm{HH} / \mathrm{FH}$ interfaces, whereas donor states generated by Fe impurities introduced during mechanical alloying are still subjected to the filtering effect. 
The large increase in the carrier density in $\mathrm{Zr}_{0.25} \mathrm{Hf}_{0.75} \mathrm{Ni}_{1+\mathrm{x}} \mathrm{Sn}_{0.995} \mathrm{Sb} 0.005$ samples resulted in a drastic drop in the carrier mobility when compared to $\mathrm{Zr}_{0.25} \mathrm{Hf}_{0.75} \mathrm{Ni}_{1+{ }_{+}} \mathrm{Sn}_{0.975} \mathrm{Sb}_{0.025}$ and $\mathrm{Zr}_{0.25} \mathrm{Hf}_{0.75} \mathrm{Ni}_{1+\mathrm{x}} \mathrm{Sn}_{0.99} \mathrm{Sb}_{0.01}$ composites. The $0.5 \% \mathrm{Sb}$-doped matrix showed the lowest mobility $\left(\sim 8 \mathrm{~cm}^{2} \mathrm{~V}^{-1} \mathrm{~s}^{-1}\right)$ at $300 \mathrm{~K}$. However, the carrier mobility rapidly increases with increasing $\mathrm{FH}$ content, reaching a maximum of $\sim 20 \mathrm{~cm}^{2} \mathrm{~V}^{-1} \mathrm{~s}^{-1}$ at $300 \mathrm{~K}$ for the composition with $\mathrm{x}=0.05$ and slightly decreases with a further increase in the $\mathrm{FH}$ content to $\mathrm{x}=0.08\left(18 \mathrm{~cm}^{2} \mathrm{~V}^{-1} \mathrm{~s}^{-1}\right.$ at $\left.300 \mathrm{~K}\right)$ and $0.15\left(14 \mathrm{~cm}^{2} \mathrm{~V}^{-1} \mathrm{~s}^{-1}\right.$ at $\left.300 \mathrm{~K}\right)$. This trend is consistent with the observed variation of carrier density with FH content. The reduction in the overall carrier density an enhancement of the carrier mobility observed in various $\mathrm{Zr}_{0.25} \mathrm{Hf}_{0.75} \mathrm{Ni}_{1+} \mathrm{SSn}_{0.995} \mathrm{Sb}_{0.005}$ samples $(\mathrm{x}=0.03,0.05,0.08$ and 0.15 ) compared to the $0.5 \% \mathrm{Sb}$-doped matrix, can be explained by the concept of energy filtering of low-energy charge carriers at the $\mathrm{HH} / \mathrm{FH}$ interfaces, which provides a plausible description of the behavior of charge carriers in $\mathrm{HH}$ matrices containing sub-ten nanometer scale FH inclusions (Figure 2A). ${ }^{[8-10]}$ However, HH matrices containing sufficiently large $\mathrm{FH}$ inclusions generally display higher carrier density than the pristine $\mathrm{HH}$ matrix (without FH inclusion) due to the metallic behavior of large FH inclusions. Additional donor states arising from the doping of the $\mathrm{HH}$ matrix by the metallic $\mathrm{FH}$ inclusions presumably occupy high energy levels (shallow states) within the band gap of the $\mathrm{HH}$ matrix facilitating their thermal excitation across the potential barrier at the $\mathrm{HH} / \mathrm{FH}$ interfaces and their contribution to the electronic conduction. ${ }^{[11]}$ This explains the slight increase in the carrier density and the drop in the carrier mobility for samples with $\mathrm{x}=0.08$ and $\mathrm{x}=0.15$ (Figure $11 \mathrm{C}$ and 11D) in which the high population density of FH nanoinclusions leads to the agglomeration of some of them into large metallic FH particles.

Figure 12 shows the temperature dependence of the total thermal conductivity, the Lorenz number and the lattice thermal conductivity for $\mathrm{FH} / \mathrm{HH}$ composites $\mathrm{Zr}_{0.25} \mathrm{Hf}_{0.75} \mathrm{Ni}_{1+\mathrm{x}} \mathrm{Sn}_{0.995} \mathrm{Sb}_{0.005}$. The total thermal conductivity increases with increasing temperature suggesting bipolar conduction (Figure 12A). Regardless of the temperature, the total thermal conductivity decreases with increasing FH content, which is consistent with the observed drop in the electrical conductivity. The total thermal conductivity for all samples is lower than that of composites with $1 \%$ and $2.5 \% \mathrm{Sb}$-doped $\mathrm{HH}$ matrix. The highest thermal conductivity, $7.2 \mathrm{WK}^{-1} \mathrm{~m}^{-1}$, is observed at $300 \mathrm{~K}$ for the $0.5 \% \mathrm{Sb}$-doped matrix and the sample with $\mathrm{x}=0.03$. 
The total thermal conductivity drastically drops to $5.7 \mathrm{WK}^{-1} \mathrm{~m}^{-1}$ at $300 \mathrm{~K}$ for samples with $\mathrm{x}=$ $0.05,0.08$ and 0.15 .

In order to analyze the electronic thermal conductivity, the Lorenz number was calculated using a SPB model (Figure 12B). The matrix and the sample with $\mathrm{x}=0.03$ have higher Lorenz number $\left(2.3 \times 10^{-8} \mathrm{~W} \Omega \mathrm{K}^{-2}\right)$ at $300 \mathrm{~K}$, which is closer to the Lorenz number for free electrons. When the FH content increases to $5 \%$, the Lorenz number decreases to $2 \times 10^{-8}{\mathrm{~W} \Omega \mathrm{K}^{-2}}$ at $300 \mathrm{~K}$. Further increasing the FH content to $8 \%$ and $15 \%$ resulted in a small increase of the Lorenz

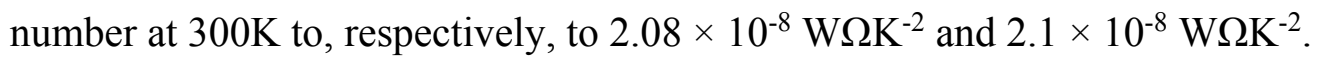

The lattice thermal conductivity decreases with increasing $\mathrm{FH}$ content. At $300 \mathrm{~K}$ the lattice thermal conductivity for the matrix is $5.3 \mathrm{WK}^{-1} \mathrm{~m}^{-1}$ and drops to $4.5 \mathrm{WK}^{-1} \mathrm{~m}^{-1}$ at $300 \mathrm{~K}$ for the sample with $x=0.15$. This corresponds to a $15 \%$ reduction compared to the $0.5 \%$ Sb-doped matrix. This reduction in the lattice thermal conductivity is attributed to enhanced phonon scattering due to a large increase in the density of $\mathrm{HH} / \mathrm{FH}$ interfaces with increasing $\mathrm{FH}$ content.

Figure 13A shows the power factor calculated using the electrical conductivity and thermopower data. The large increase in the thermopower induced by the energy filtering of carriers at $\mathrm{HH} / \mathrm{FH}$ nanointerfaces, offsets the reduction in the electrical conductivity leading to an improvement in the overall powder factor for samples with $\mathrm{x}=0.03,0.05,0.08$ and 0.15 . The sample with $\mathrm{x}=0.05$ showed the highest value of the PF in the measured temperature range. The combination of the large improvement in the power factor and the reduction in the thermal conductivity in the sample with $\mathrm{x}=0.05$ resulted in drastic increase of the ZT at $775 \mathrm{~K}$ from $\sim 0.05$ for $0.5 \%$ Sb-doped matrix to $\sim 0.24$, which corresponds to an enhancement of $\sim 67 \%$.

\section{Conclusion}

In summary, we have investigated the effectiveness of the potential energy barrier, $\Delta \mathrm{E}$, at $\mathrm{HH} / \mathrm{FH}$ interfaces in filtering charge carriers within $\mathrm{HH}$ matrix with various doping levels. We found that starting from $\mathrm{HH}$ matrices containing equal volume fractions of $\mathrm{FH}$ nanoinclusions with similar average size range, the magnitude of the energy-filtering effect by the potential energy barrier at the $\mathrm{HH} / \mathrm{FH}$ interfaces strongly depends on the energy distribution of donor states within the band gap of the $\mathrm{HH}$ matrix. In this work, carriers in various $\mathrm{HH}$ matrices $\left(\mathrm{Zr}_{0.25} \mathrm{Hf}_{0.75} \mathrm{NiSn}_{1-\mathrm{y}} \mathrm{Sb}_{\mathrm{y}}\right)$ were introduced either intentionally using Sb substitutions at $\mathrm{Sn}$ sites or unintentionally through doping of the matrix by (1) large metallic FH inclusions and/or (2) by Fe 
impurities introduced during the mechanical alloying process. These dopants presumably provide donor states with various energy levels within the band gap of the HH matrix. We observed that for $\mathrm{Zr}_{0.25} \mathrm{Hf}_{0.75} \mathrm{Ni}_{1++\times} \mathrm{Sn}_{1-\mathrm{y}} \mathrm{Sb}_{\mathrm{y}}$ samples in which electronic conduction is dominated by charge carriers from donor states of $\mathrm{Sb}$ dopant and metallic FH inclusions $(\mathrm{y}=0.01$ and 0.025$)$, the introduction of $\mathrm{HH} / \mathrm{FH}$ interfaces through addition of excess elemental $\mathrm{Ni}$ (x) resulted in a constant or a marginal drop of the overall carriers density compared to the pristine $\mathrm{HH}$ matrix. This suggests that a large fraction of donor states in these samples are located at high energy levels (shallow states) within the band gap of HH matrix facilitating their thermal excitation across the potential energy barrier at the $\mathrm{HH} / \mathrm{FH}$ interfaces. Therefore, the low-energy intrinsic carriers trapped at the $\mathrm{HH} / \mathrm{FH}$ interfaces represent a very small fraction of conduction electrons leading to virtually no effect on the overall effective carrier density. However, for the mechanically alloyed $\mathrm{Zr}_{0.25} \mathrm{Hf}_{0.75} \mathrm{Ni}_{1+\times} \mathrm{Sn}_{0.995} \mathrm{Sb}_{0.005}$ samples, we observed a drastic decrease in the effective carrier density upon introduction of $\mathrm{HH} / \mathrm{FH}$ interfaces. This suggests that a large fraction of donor states in these samples are located at low energy levels (deep states) within the band gap of the $\mathrm{HH}$ matrix and therefore require higher temperature to overcome the potential barrier at the $\mathrm{HH} / \mathrm{FH}$ interface. One can derive from this analysis that donor states introduced by Fe impurities during the mechanical alloying process occupy lower energy levels (deep states) within the $\mathrm{HH}$ matrix, whereas donor states from $\mathrm{Sb}$ doping at $\mathrm{Sn}$ sites or from the formation of metallic FH inclusions are located at higher energy levels (hallow states). This work demonstrates the effectiveness of the potential energy barrier at $\mathrm{HH} / \mathrm{FH}$ interfaces to discriminate between dopants inducing donor states with various energy levels in $\mathrm{HH}$ semiconductors. Therefore, the optimization of the thermoelectric properties of semiconductors through synergistic integration of the concepts of doping and energy-filtering through nanostructuring requires a good match between (1) the type of doping elements (energy level occupied by impurity states) and (2) the average size and distribution (the heights of the potential energy barrier) of the nanostructures coherently embedded inside the semiconducting matrix.

\section{Acknowledgements}

We gratefully acknowledge the financial support from the Department of Energy, Office of Basic Energy Science under Award \# DE-SC-0008574. This work made use of the TEM from the 
Michigan Materials Characterization Center, $(\mathrm{MC})^{2}$, purchased with funds from the National Science Foundation Awards DMR-0315633 and DMR-0723032.

\section{Reference}

[1] L. D. Zhao, V. P. Dravid, M. G. Kanatzidis, Energy \& Environmental Science 7 (2014) 251.

[2] J. R. Sootsman, D. Y. Chung, M. G. Kanatzidis, Angewandte Chemie-International Edition 48 (2009) 8616.

[3] M. G. Kanatzidis, Chemistry of Materials 22 (2010) 648.

[4] A. J. Minnich, M. S. Dresselhaus, Z. F. Ren, G. Chen, Energy \& Environmental Science 2 (2009) 466.

[5] G. J. Snyder, E. S. Toberer, Nature Materials 7 (2008) 105.

[6] Y. F. Liu, A. Page, P. Sahoo, H. Chi, C. Uher, P. F. P. Poudeu, Dalton Transactions 43 (2014) 8094.

[7] P. Sahoo, Y. F. Liu, P. F. P. Poudeu, Journal of Materials Chemistry A 2 (2014) 9298.

[8] Y. F. Liu, P. Sahoo, J. P. A. Makongo, X. Y. Zhou, S. J. Kim, H. Chi, C. Uher, X. Q. Pan, P. F. P. Poudeu, Journal of the American Chemical Society 135 (2013) 7486.

[9] P. Sahoo, Y. F. Liu, J. P. A. Makongo, X. L. Su, S. J. Kim, N. Takas, H. Chi, C. Uher, X. Q. Pan, P. F. P. Poudeu, Nanoscale 5 (2013) 9419.

[10] J. P. A. Makongo, D. K. Misra, J. R. Salvador, N. J. Takas, G. Y. Wang, M. R. Shabetai, A. Pant, P. Paudel, C. Uher, K. L. Stokes, P. F. P. Poudeu, Journal of Solid State Chemistry 184 (2011) 2948.

[11] J. P. A. Makongo, D. K. Misra, X. Y. Zhou, A. Pant, M. R. Shabetai, X. L. Su, C. Uher, K. L. Stokes, P. F. P. Poudeu, Journal of the American Chemical Society 133 (2011) 18843.

[12]L. D. Zhao, J. Q. He, S. Q. Hao, C. I. Wu, T. P. Hogan, C. Wolverton, V. P. Dravid, M. G. Kanatzidis, Journal of the American Chemical Society 134 (2012) 16327.

[13] L. D. Zhao, J. Q. He, C. I. Wu, T. P. Hogan, X. Y. Zhou, C. Uher, V. P. Dravid, M. G. Kanatzidis, Journal of the American Chemical Society 134 (2012) 7902.

[14]B. Yu, M. Zebarjadi, H. Wang, K. Lukas, H. Z. Wang, D. Z. Wang, C. Opeil, M. Dresselhaus, G. Chen, Z. F. Ren, Nano Letters 12 (2012) 2077.

[15]K. Biswas, J. Q. He, Q. C. Zhang, G. Y. Wang, C. Uher, V. P. Dravid, M. G. Kanatzidis, Nature Chemistry 3 (2011) 160. 
[16] K. Biswas, I. Chung, J. H. Song, C. D. Malliakas, A. J. Freeman, M. G. Kanatzidis, Inorganic Chemistry 52 (2013) 5657.

[17] W. Jeitschko, Metall. Trans. 1 (1970) 3159.

[18] P. J. Webster, K. R. A. Ziebeck, Landolt-Börnstein-group III condensed matter, Vol. 19C, Berlin: Springer, 1988.

[19] F. Heusler, Verh. Dtsch. Phys. Ges. 5 (1903) 219.

[20] F. Heusler, W. Starck, E. Haupt, Verh. Dtsch. Phys. Ges 5 (1903) 220.

[21] O. Heusler, Ann. Phys. 19 (1934) 155.

[22] A. J. Bradley, J. W. Rodgers, Proc Roy Soc A 144 (1934) 340.

[23] R. Yaqub, P. Sahoo, J. P. A. Makongo, N. Takas, P. F. P. Poudeu, K. L. Stokes, Science of Advanced Materials 3 (2011) 633.

[24] S. R. Culp, J. W. Simonson, S. J. Poon, V. Ponnambalam, J. Edwards, T. M. Tritt, Applied Physics Letters 93 (2008) 022105.

[25] S. J. Poon, in Semiconductor and Semimetals, Vol. 70 (Ed.: T. M. Tritt), Academic, New York, 2001, pp. 37.

[26] X. Yan, G. Joshi, W. Liu, Y. Lan, H. Wang, S. Lee, J. W. Simonson, S. J. Poon, T. M. Tritt, G. Chen, Z. F. Ren, Nano Letters 11 (2011) 556.

[27] G. Joshi, X. Yan, H. Z. Wang, W. S. Liu, G. Chen, Z. F. Ren, Advanced Energy Materials 1 (2011) 643.

[28]Y. C. Lan, A. J. Minnich, G. Chen, Z. F. Ren, Advanced Functional Materials 20 (2010) 357.

[29] T. M. Tritt, H. Bottner, Journal of Materials Research 26 (2011) 1743.

[30] J. W. Simonson, D. Wu, W. J. Xie, T. M. Tritt, S. J. Poon, Physical Review B 83 (2011).

[31] P. F. Poudeu, J. Salvador, J. Sakamoto, Science of Advanced Materials 3 (2011) 515.

[32] W. J. Xie, J. He, S. Zhu, X. L. Su, S. Y. Wang, T. Holgate, J. W. Graff, V. Ponnambalam, S. J. Poon, X. F. Tang, Q. J. Zhang, T. M. Tritt, Acta Materialia 58 (2010) 4705.

[33] P. Maji, N. J. Takas, D. K. Misra, H. Gabrisch, K. Stokes, P. F. P. Poudeu, Journal of Solid State Chemistry 183 (2010) 1120.

[34]F. G. Aliev, N. B. Brandt, V. V. Moshchalkov, V. V. Kozyrkov, R. V. Skolozdra, A. I. Belogorokhov, Zeitschrift Fur Physik B-Condensed Matter 75 (1989) 167.

[35]F. G. Aliev, V. V. Kozyrkov, V. V. Moshchalkov, R. V. Scolozdra, K. Durczewski, Zeitschrift Fur Physik B-Condensed Matter 80 (1990) 353. 
[36] J. W. Simonson, S. J. Poon, J. Phys.: Condens. Matter 20 (2008) 255220.

[37] J. Barth, B. Balke, G. H. Fecher, H. Stryhanyuk, A. Gloskovskii, S. Naghavi, C. Felser, Journal of Physics D-Applied Physics 42 (2009).

[38] L. Chaput, J. Tobola, P. Pecheur, H. Scherrer, Physical Review B 73 (2006) 045121.

[39] S. Sakurada, N. Shutoh, Applied Physics Letters 86 (2005) 082105.

[40] C. Uher, J. Yang, S. Hu, D. T. Morelli, G. P. Meisner, Physical Review B 59 (1999) 8615.

[41] B. R. K. Nanda, I. Dasgupta, Journal of Physics-Condensed Matter 17 (2005) 5037.

[42] K. Kroth, B. Balke, G. H. Fecher, V. Ksenofontov, C. Felser, H. J. Lin, Applied Physics Letters 89 (2006) 202509.

[43] S. Ouardi, G. H. Fecher, B. Balke, X. Kozina, G. Stryganyuk, C. Felser, S. Lowitzer, D. Kodderitzsch, H. Ebert, E. Ikenaga, Physical Review B 82 (2010) 085108.

[44] B. Sanyal, O. Eriksson, K. G. Suresh, I. Dasgupta, A. K. Nigam, P. Nordblad, Applied Physics Letters 89 (2006) 212502.

[45]H. Lin, L. A. Wray, Y. Q. Xia, S. Y. Xu, S. A. Jia, R. J. Cava, A. Bansil, M. Z. Hasan, Nature Materials 9 (2010) 546.

[46] S. Chadov, X. L. Qi, J. Kubler, G. H. Fecher, C. Felser, S. C. Zhang, Nature Materials 9 (2010) 541.

[47]D. Xiao, Y. G. Yao, W. X. Feng, J. Wen, W. G. Zhu, X. Q. Chen, G. M. Stocks, Z. Y. Zhang, Physical Review Letters 105 (2010) 096404.

[48] A. Page, C. Uher, P. F. Poudeu, A. Van der Ven, Physical Review B 92 (2015) 174102.

[49] A. F. May, E. S. Toberer, A. Saramat, G. J. Snyder, Physical Review B 80 (2009) 125205.

[50] A. May, G. Snyder, D. Rowe, CRC Press Boca Raton, FL, 2012. 


\section{Table of Contents Synopsis}

Distribution of impurity states and charge transport in $\mathrm{Zr}_{0.25} \mathrm{Hf}_{0.75} \mathrm{Ni}_{1+\mathrm{x}} \mathrm{Sn}_{1-\mathrm{y}} \mathrm{Sb}_{\mathrm{y}}$ nanocomposites

Yuanfeng Liu ${ }^{1} \neq$, Julien P.A. Makongo ${ }^{1}$;, Alexander Page ${ }^{2}$, Pranati Sahoo ${ }^{1}$, Ctirad Uher ${ }^{2}$, Kevin Stokes $^{3}$, Pierre F.P. Poudeu ${ }^{1, *}$

\section{Graphical abstract}

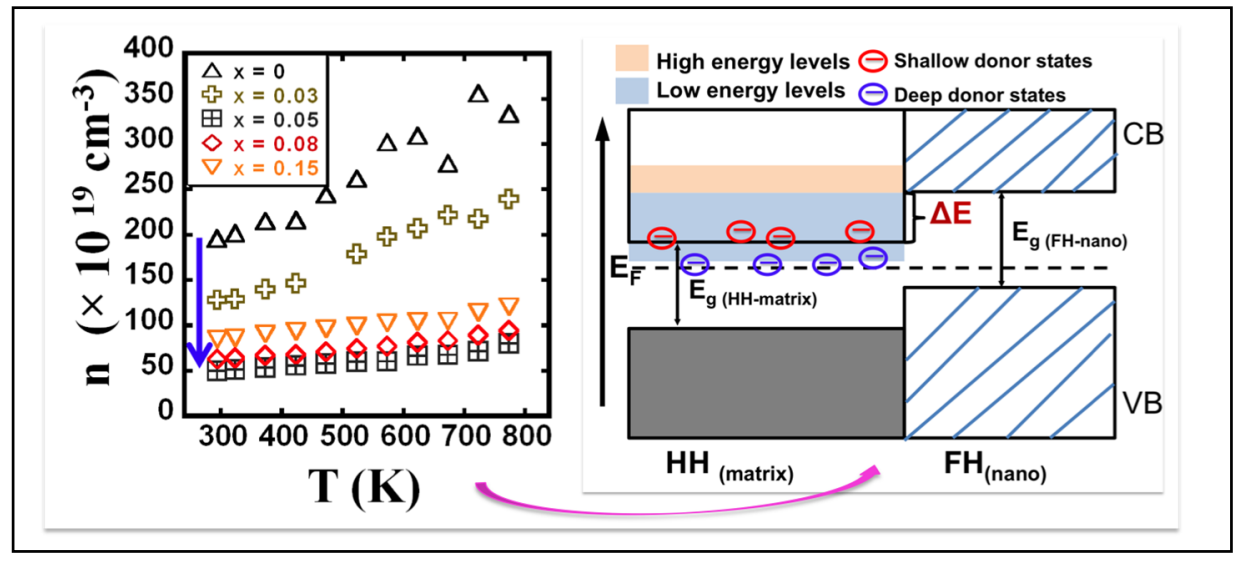

Electronic transport in semiconducting half-Heusler $(\mathrm{HH})$ matrices containing full-Heusler $(\mathrm{FH})$ nanoinclusions strongly depends on the energy distribution of impurity states within the $\mathrm{HH}$ matrix with respect to the magnitude of the potential energy barrier at the $\mathrm{HH} / \mathrm{FH}$ interfaces. 